\title{
A bias-corrected CMIP6 global dataset for dynamical downscaling of future climate, 1979- 2100
}

\section{Zhongfeng Xu ( $\sim$ xuzhf@tea.ac.cn )}

Institute of Atmospheric Physics, Chinese Academy of Sciences

\section{Ying Han}

Institute of Atmospheric Physics, Chinese Academy of Sciences

Chi-Yung Tam

Earth System Science Programme, The Chinese University of Hong Kong https://orcid.org/0000-00025462-6880

\section{Zong-Liang Yang}

Department of Geological Sciences, Jackson School of Geosciences, The University of Texas at Austin https://orcid.org/0000-0003-3030-0330

\section{Congbin Fu}

School of Atmospheric Sciences, Nanjing University

\section{Research Article}

Keywords: CMIP6, bias correction, dynamical downscaling

Posted Date: April 15th, 2021

DOl: https://doi.org/10.21203/rs.3.rs-424811/v1

License: (9) This work is licensed under a Creative Commons Attribution 4.0 International License. Read Full License 


\title{
A bias-corrected CMIP6 global dataset for dynamical downscaling of future climate, 1979-2100
}

Authors

Zhongfeng $\mathrm{Xu}^{1}$, Ying $\mathrm{Han}^{1}$, Chi-Yung Tam ${ }^{2}$, Zong-Liang Yang ${ }^{3}$, Congbin $\mathrm{Fu}^{4}$

\section{Affiliations}

1. RCE-TEA, Institute of Atmospheric Physics, Chinese Academy of Sciences, Beijing, 100029, China

2. Earth System Science Programme, The Chinse University of Hong Kong, Hong Kong, China

3. Department of Geological Sciences, Jackson School of Geosciences, The University of Texas at Austin, Austin, Texas, USA

4. School of Atmospheric Sciences, Nanjing University, 210093, Nanjing, China corresponding author: Zhongfeng Xu (xuzhf@tea.ac.cn)

\begin{abstract}
Dynamical downscaling is an important approach to obtaining fine-scale weather and climate information. However, dynamical downscaling simulations are often degraded by biases in the large-scale forcing itself. Here, we construct a set of bias-corrected global datasets based on 18 models from the Coupled Model Intercomparison Project Phase 6 (CMIP6) and European Centre for Medium-Range Weather Forecasts Reanalysis 5 (ERA5). The biascorrected data have an ERA5-based mean climate and interannual variance, but with a nonlinear trend from the mean of 18 CMIP6 models. The dataset spans the historical period of 1979-2014 and future scenarios (SSP245 and SSP585) of 2015-2100 with a horizontal resolution of $1.25^{\circ} \times 1.25^{\circ}$ and 6 -hourly intervals. Our evaluation suggests that the biascorrected data shows clearly better quality than individual CMIP6 models evaluated in terms of climatological mean, interannual variance and extreme events. The presented dataset will be useful for the dynamical downscaling projections of future climate, atmospheric environment, hydrology, agriculture, wind power, etc.
\end{abstract}

\section{Background \& Summary}

Projection of future climate at a finer scale is of great importance to the climate-related studies, such as climate extremes, water resources, agriculture, air quality, and wind power. Common approaches to produce high-resolution projection data include interpolation ${ }^{1,2}$, statistical downscaling ${ }^{3,4}$, dynamical downscaling ${ }^{5-8}$, and hybrid statistical-dynamical downscaling ${ }^{9,10}$. Compared to the interpolation and statistical downscaling, dynamical downscaling can represent various physical processes as well as their interaction in the climate system, and generate a full set of dynamically consistent high-resolution climate data. Traditional dynamical downscaling (TDD) of future climate involves integrating a regional climate model (RCM) with initial conditions, lateral boundary conditions from a $\mathrm{GCM}^{6,11}$. This TDD approach has been widely used in previous studies ${ }^{12,13}$. However, GCMs are known to have significant biases, which propagate into RCMs through the lateral boundary and thus degrade the downscaled simulations ${ }^{14-16}$.

In recent years, GCM bias corrections are becoming a hot topic in dynamical downscaling studies and many GCM bias correction methods have been developed, e.g., GCM mean bias correction ${ }^{17-19}$, GCM mean and variance bias corrections ${ }^{16,20}$, Quantilequantile correction $^{21}$, nested bias correction ${ }^{22}$ and multi-model ensemble (MME) meanbased bias correction ${ }^{23}$. Compared to the TDD approach, these bias-correction methods significantly improve downscaling simulations. For example, GCM mean bias correction clearly improved the dynamical downscaling simulation of tropical cyclones over the North Atlantic Ocean ${ }^{18,19}$. The introduction of variance bias correction further improved the 
downscaled interannual variability and extreme events ${ }^{16}$. MME-based bias correction is expected to generate a more credible downscaling projection of future climate ${ }^{23}$.

On the other hand, current GCM bias-correction methods also have limitations ${ }^{24,25}$. For example, Bruyère et al (2014) only corrected GCM mean bias and leave other biases untouched $^{19}$. In terms of long-term dynamical downscaling, the variance bias correction may inappropriately modify the GCM trend ${ }^{16}$. The quantile-quantile correction cannot retain the intervariable dependencies and introduces an additional bias in the spatial gradient of variables $^{21,26}$. Note that most bias correction methods are applied to a single model dataset, which suffers greater uncertainty in terms of the projection of future climate. Dai et al. (2017) applied GCM bias correction to MME mean of CMIP5 models. However, they only corrected the GCM mean bias ${ }^{23}$.

It is well known that the climate projections generated by GCMs are still highly uncertain, especially for precipitation and its extremes ${ }^{27}$. The source of uncertainties includes the future emission scenarios, internal climate variability, and model uncertainty ${ }^{28}$. These uncertainties hinder the application of climate projection in impact studies, e.g., the impact of future climate change on water resources and agriculture. Here, we constructed a set of bias-corrected GCM data based on a novel GCM bias correction method. The method takes advantage of the non-linear trend of ensemble mean of 18 Coupled Model Intercomparison Project Phase 6 (CMIP6) models to give a more reliable projection of the long-term climate trend on one hand. On the other hand, we also correct the GCM climatological mean and interannual variance biases based on ERA5. The bias corrections were applied to historical simulations over the period of 1979-2014 and two future scenarios of SSP245 and SSP585 over the period of 2015-2100. This bias-corrected dataset is expected to provide a high-quality large-scale forcing for dynamical downscaling simulation and to improve the reliability of future projections of regional climate and environment.

\section{Methods}

Data acquisition. We used the monthly data derived from the CMIP6 historical experiment and future scenarios of SSP245 and SSP585 ${ }^{29}$. The multi-model ensemble mean (MME) of each experiment were calculated using 18 CMIP6 models (Table 1). Previous studies suggested that the MPI-M Earth system models show generally good performance in the simulation of SST and atmospheric circulation among the CMIP5 and CMIP6 models ${ }^{30,31}$. We, therefore, select the 6-hourly dataset produced by the high-resolution version of the MPI-M earth system model (MPI-M1-2-HR) in CMIP6 to generate weather and interannual variability of the large-scale forcing data. The MPI-ESM1-2-HR is configured with a horizontal grid spacing of $100 \mathrm{~km}$ in the atmosphere and $40 \mathrm{~km}$ in the ocean ${ }^{32}$. Compared with its lowresolution counterpart MPI-ESM1.2-LR, MPI-ESM1-2-HR shows improved performance in mid-latitude storm track dynamics, atmospheric blocking, and quasi-biennial oscillation, although the improvement in the mean state relatively modest ${ }^{32-34}$. The variables used include upper-air temperature, zonal wind, meridional wind, relative humidity, geopotential height, as well as surface pressure, sea level pressure, and sea surface temperature.

We also used the ERA5 reanalysis data from 1979 to 2014, which is produced by the European Centre for Medium-Range Weather Forecasts Reanalysis (ECMWF) using 4D-var data assimilation ${ }^{35}$. Compared to ERA-Interim, ERA5 has a higher horizontal resolution of $31 \mathrm{~km}$ and with more observations assimilated. ERA5 shows considerable improvement in tropospheric temperature, wind, and humidity, but not in the stratosphere with respect to ERA-Interim. Both the ERA5 and CMIP6 data were regrided to a horizontal resolution of $1.25^{\circ}$ longitude $\times 1.25^{\circ}$ latitude by bilinear interpolation.

GCM bias-correction method. The bias corrections are applied to 6-hourly data. Each nonleap year contains 1460 data points. For each 6-hour and day of the year, the ERA reanalysis 
(orange curve in Fig.1) and GCM output (red curve in Fig.1) can be broken down into a longterm nonlinear trend plus an interannual perturbation term:
$\mathrm{GCM}=\mathrm{GCM}_{L T}+\mathrm{GCM}^{\prime}$
$\mathrm{ERA}=\mathrm{ERA}_{L T}+E R A^{\prime}$

The nonlinear trend was calculated with the EEMD method ${ }^{36}$. Unlike the previous decomposition that broke the GCM into a climatological mean plus a perturbation term as in previous studies ${ }^{16,17}$, our decomposition excludes the long-term trend in the perturbation term, which can avoid inappropriate modification on the long-term trend during the variance bias correction. Note that the GCM may also overestimate or underestimate the amplitude of interannual variations. This bias can be measured by the ratio of GCM variance to reanalysis variance. We assume that the variance bias remains the same from the historical to a future period. Thus, we can correct the variance bias by multiplying the perturbation term by a scaling factor, $\mathrm{r}_{s}$ :

$\mathrm{GCM}_{v}=\mathrm{GCM}_{L T}+\mathrm{GCM}^{\prime} \times \mathrm{r}_{s}$

where $\mathrm{r}_{S}=\sigma_{E R A} / \sigma_{G C M}$ is the ratio of the standard deviation of detrended reanalysis to that of detrended GCM over the historical period. As the standard deviations are computed using detrended data, we, therefore, adjust the variance of interannual and interdecadal variation and remain the nonlinear trend unchanged (blue curve in Fig.1). Otherwise, the long-term trend may also be changed inappropriately if we use the standard deviation of the original time series to adjust the variance ${ }^{38}$.

It is known that single-GCM projections of long-term trend give greater uncertainty compared to the MME mean. To reduce the certainty of future projection, we replace the long-term nonlinear trend derived from the single GCM with that derived from MME in Eq. (3). Thus the new GCM data (green curve in Fig.1) can be rewritten as:

$\mathrm{GCM}_{v t}=\mathrm{MME}_{L T}+\mathrm{GCM}^{\prime} \times \mathrm{r}_{s}$

$\mathrm{MME}_{L T}$ is the nonlinear trend of MME computed with EEMD over the historical-future period. Eq. (4) can be further rearranged according to:

$\mathrm{GCM}_{v t}=\mathrm{MME}_{L T}+\left(\overline{\left.\mathrm{MME}_{L T}\right|_{H}}-\overline{\left.\mathrm{ERA}_{L T}\right|_{H}}\right)-\left(\overline{\left.\mathrm{MME}_{L T}\right|_{H}}-\overline{\left.\mathrm{ERA}_{L T}\right|_{H}}\right)+\mathrm{GCM}^{\prime} \times \mathrm{r}_{S}$

The subscript $H$ represents the historical period (1979-2014), while the overbar indicates the climatological mean. $\left(\overline{\left.\mathrm{MME}_{L T}\right|_{H}}-\overline{\left.\mathrm{ERA}_{L T}\right|_{H}}\right)$ is the mean bias of GCM long-term trend relative to that of the reanalysis over the historical period, which can be removed to correct the GCM mean bias. Further bias-corrected data can be constructed as follows:

$$
\begin{aligned}
\mathrm{GCM}_{v t m} & =\mathrm{MME}_{L T}-\left(\overline{\left.\mathrm{MME}_{L T}\right|_{H}}-\overline{\left.\mathrm{ERA}_{L T}\right|_{H}}\right)+\mathrm{GCM}^{\prime} \times \mathrm{r}_{S} \\
& =\overline{\left.\mathrm{ERA}_{L T}\right|_{H}}+\left(\mathrm{MME}_{L T}-\overline{\left.\mathrm{MME}_{L T}\right|_{H}}\right)+\mathrm{GCM}^{\prime} \times \mathrm{r}_{S}
\end{aligned}
$$

Thus, the bias-corrected 6-hourly GCM data over the future period have a base climate provided by reanalysis data over the historical period, with the change in future climate relative to the historical climatology generated by $\mathrm{MME}$, and future bias-corrected weather and climate variability derived from a single GCM. Eq. (6) is the final equation that corrects GCM mean and variance biases after replacing the single GCM nonlinear trend with the MME nonlinear trend (black curve in Fig.1).

The EEMD method used to compute the nonlinear trend is very time-consuming if we apply EEMD to process global 6-hourly 3-D data sets over multiple decades. To save computing time, we assume that the nonlinear trends remain the same for each 6hourly/daily value of variables within the same month. Thus, the climatological mean of the detrended data, $\frac{1}{N} \sum_{i=1}^{N}\left(G C M-G C M_{L T}\right)$, is not exactly equal to zero because the GCM and $G C M_{L T}$ are derived from 6-hourly data and monthly data, respectively. Before correcting the variance biases, we compute the anomaly of detrended GCM data at each 6-hourly interval/day of the year:

$\mathrm{GCM}^{\prime}=\left(G C M-G C M_{L T}\right)-\frac{1}{N} \sum_{i=1}^{N}\left(G C M-G C M_{L T}\right)$

The first term on the right-hand side of Eq. (7) represents the detrended GCM data. The standard deviation of each 6-hour and day of the year is calculated across 36 years from 
1979 to 2014. Note that extreme events, e.g., tropical cyclone, can strongly affect the interannual standard deviations of many variables, such as the sea level pressure, geopotential height, and wind. As tropical cyclones occur in different locations in the CMIP6 model and reanalysis, the ratio of standard deviation in the grid cells with tropical cyclones would be unrealistically different from its surrounding regions. To remove the unrealistic ratios of standard deviation, we first calculate the original standard deviation with all 36 years of data and then recalculate the standard deviation after removing the years with anomalies greater than 3 times the original standard deviation.

Evaluation methods. To comprehensively compare the performance of bias-corrected GCM data with other CMIP6 models, we computed the commonly used statistics, such as mean error (ME), correlation coefficient (CORR), standard deviation (SD), and root-mean-square difference (RMSD). To assess the overall performance of climate model in simulating multiple fields, we also employed a multivariable integrated skill score (MISS). MISS is defined based on the vector fields statistics and can summarize the model overall performance in simulating multiple fields ${ }^{38-40}$. Model performance improves monotonically with an increase in MISS. MISS approaches 1 when the modeled multiple fields are close to observed values. Thus, MISS can be used to rank the performance of various CMIP6 models in simulating multiple fields.

\section{Data Records}

The dataset includes 3 surface variables and 8 upper-air variables for three sets of biascorrected CMIP6 data, the historical data from 1979 to 2014, SSP245 and SSP585 from 2015 to 2100 (Table 2). We provide the data at a horizontal resolution of $1.25^{\circ}$ longitude $\times 1.25^{\circ}$ and 6 hourly interval. The upper-air variables consist of 14 pressure levels, i.e., 1000, 925, $850,700,600,500,400,300,250,200,150,100,70$, and $50 \mathrm{hPa}$. All the bias-corrected data was stored in self-describing NetCDF format (http://doi.org/10.5065/D6H70CW6). The NetCDF files are named as "atm_experiment_yyyy_mm.nc4", where "experiment" denotes the historical, SSP245, or SSP585 experiments. "yyyy" and "mm" denote the year and month of the data, respectively. Each file includes all 6-hourly data for one month of a year. The complete data set is $\sim 1.9$ TB in size. All data are freely available at the China Science Data Bank $^{41}$.

\section{Technical Validation}

Time series. To validate the bias-correction GCM data, we compared the 600-hPa air temperature in Northwest Pacific derived from the original GCM, bias-corrected GCM (GCMbc), and ERA5 in Fig. 2. The original GCM data overestimate air temperature by $1.37^{\circ} \mathrm{C}$ over the historical period (1979-2014) relative to ERA5 (Fig. 2a). The mean bias is completely removed in the bias-corrected GCM data. Compared to ERA5, the original GCM underestimates the amplitude of interannual variability characterized by a standard deviation of 0.54 in GCM against 0.85 in ERA5. The variance bias is also removed in the biascorrected GCM data. Besides, the GCM and GCMbc show different long-term trends because the GCMbc follows the non-linear trend of MME of 18 CMIP5 models. Note that the bias correction method proposed in this study affects the GCM mean, variance, and non-linear trend but does not affect the phase of interannual variation. GCMbc inherits the phase of interannual variation from the selected GCM, i.e., MPI-ESM1-2-HR.

The frequency distribution of $600-\mathrm{hPa}$ air temperature indicates that the GCM significantly overestimates the high-temperature events but underestimate the lowtemperature ones relative to ERA5 (Fig. 2b). In contrast, the bias-corrected GCM, i.e. GCMbc, shows a frequency distribution very similar to that from ERA5. This indicates that the bias correction methods can also significantly improve the GCM extreme events characteristics. 
Under the SSP585 scenario (Fig. 2c), the temperature is a non-stationary time series in association with global warming. Consequently, the frequency distribution of temperature does not follow a normal distribution. The change in the frequency distribution during the future period is similar to that during the historical periods characterized by a shift towards a colder climate and an enhanced variance.

Climatological mean. The climatology of the bias-corrected GCM data and 18 CMIP6 models are assessed against ERA5 with multiple statistics, e.g., mean error (ME), spatial standard deviation (SD), and correlation coefficient (CORR) for multiple variables. All statistics were normalized by dividing the observed standard deviation of the corresponding variable to facilitate the intercomparison between different variables. The results suggest that CMIP6 models show greater ME of 200-hPa air temperature and $850-\mathrm{hPa}$ relative humidity (Fig. 3). Most CMIP6 models underestimate the $200-\mathrm{hPa}$ air temperature, as indicated by negative MEs ranging from 0.3 to 2 times of standard deviation. On the other hand, 12 out of 18 CMIP6 models significantly overestimate the $850-\mathrm{hPa}$ relative humidity by $\sim 0.3-2$ standard deviation. CMIP6 models also show relatively poor performance in the spatial pattern of 200$\mathrm{hPa}$ air temperature and $850-\mathrm{hPa}$ relative humidity characterized by smaller CORR than other variables. For the climatological mean of multiple variables, EC-Earth3, EC-Earth3-Veg, AWI-CM-1-1-MR, GFDL-CM4, and MPI-ESM1-2-HR ranks the top 5 out of 18 CMIP6 models. The mean errors in the bias-corrected GCM data (MPI-ESM1-2-HR_bc) are completely removed. In another word, the climatology of the bias-corrected GCM is the same as those of ERA5 during the historical period.

Extreme values. The extreme values in the large-scale forcing data will likely affect the RCM simulations through the lateral and underlying boundary conditions. To examine the impacts of bias corrections on extreme values, we calculate the 95 percentile of daily SST and 850hPa wind speed during July of 1979-2014 (Fig. 4). The GCM (i.e., MPI-ESM1-2-HR) overestimates the high SST extreme over the Intertropical Pacific convergence zone and South Pacific convergence zone by $1-2^{\circ} \mathrm{C}$ but underestimate the high SST extreme by approximately $-2{ }^{\circ} \mathrm{C}$ in the central North Pacific and Atlantic Oceans (Fig. 4c). In the biascorrected GCM data, the bias of high SST extreme is generally less than $0.5^{\circ} \mathrm{C}$ except in the eastern coast of the central Pacific where there is a negative bias of about $-1{ }^{\circ} \mathrm{C}$ (Fig. 4e). Wind is another key variable that transfers energy and moisture into RCM through the LBC. The RCM simulation is strongly affected by the wind circulation, especially that with an inward component ${ }^{42,43}$. The GCM significantly overestimates the $850-\mathrm{hPa}$ wind speed over East Asia, South Europe-West Asia, and western North America by approximately 3-5 m s $\mathrm{s}^{-1}$ but underestimates that over most parts of the Pacific Ocean (Fig. 4d). These biases are significantly reduced in the bias-corrected GCM data with typical wind speed bias less than 1 $\mathrm{m} \mathrm{s}^{-1}$. Note that we did not directly correct the biases of extreme values per se. However, the bias correction to mean and variance biases will in turn improve the extreme values.

Long-term nonlinear trends. Figure 5 illustrates the non-linear trends of January-mean 850$\mathrm{hPa}$ air temperature from 2015 to 2100 . To facilitate intercomparison of various models, each of the non-linear trends subtracts its value in the year 2015. Under the SSP585 scenario, CMIP6 models show a $3-6.8^{\circ} \mathrm{C}$ increase in the non-linear trend of global mean $850-\mathrm{hPa}$ air temperature across 18 CMIP6 models by the end of the 21st century. Clearly, CMIP6 models still show a large uncertainty in the projection of global mean $850-\mathrm{hPa}$ air temperature. Same as MME, the bias-corrected GCM shows a $4.2^{\circ} \mathrm{C}$ increase in $850-\mathrm{hPa}$ air temperature against the $3.5^{\circ} \mathrm{C}$ increase in the MPI-ESM1-2-HR model by the end of the 21st century.

To more comprehensively compare the difference in non-linear trend among various CMIP6 models, we computed the CRMSD of the non-linear trend of each model relative to that of MME (Fig. 5b). A smaller CRMSD indicates that the non-linear trend of the 
corresponding model is closer to that of MME. Compared to all of the CMIP6 models evaluated, the bias-corrected GCM shows the minimum CRMSE for all variables. The CRMSEs are reduced by approximately $70-90 \%$ after bias corrections. Note that the non-linear trend of bias-corrected GCM should be the same as that of MME for each 6 hours and day of the year. However, the non-linear trends in figure $5 \mathrm{~b}$ were computed using monthly mean data rather than the 6-hourly data. The anomalous time series are multiplied by different scaling factors on different days during the variance bias correction. Thus, the monthly mean of the bias-corrected data will show non-linear trends slightly different from those of MME.

Intervariable dependency. It was argued that the independent bias correction to individual variables can disturb the intervariable dependency, which may degrade the RCM simulation to a certain extent ${ }^{26,44}$. To examine the impacts of bias correction on the intervariable dependency, we computed the geostrophic wind based on the geostrophic balance

$$
\begin{aligned}
& u_{g}=-\frac{1}{f}\left(\frac{\partial \mathrm{gz}}{\partial y}\right)_{p} \\
& v_{g}=-\frac{1}{f}\left(\frac{\partial \mathrm{gz}}{\partial x}\right)_{p}
\end{aligned}
$$

where $u_{g}$ and $v_{g}$ are the zonal and meridional components of geostrophic wind, respectively, $g$ the acceleration of gravity, $z$ the geopotential height, $f$ the Coriolis parameter. The geostrophic wind is a result of the balance between the horizontal pressure gradient and Coriolis force. The ageostrophic wind, i.e., geostrophic wind deviation, is defined by the vector difference between the real wind and the geostrophic wind:

$$
\begin{aligned}
& u_{a}=u-u_{g} \\
& v_{a}=v-v_{g}
\end{aligned}
$$

The ratio of ageostrophic wind speed to the real wind speed is calculated by

$$
\mathrm{R}=\frac{\sqrt{u_{a}^{2}+v_{a}^{2}}}{\sqrt{u^{2}+v^{2}}}
$$

$\mathrm{R}$ can also be interpreted as the percentage of geostrophic wind deviation to real wind speed. In general, $R$ is expected to increase if the bias correction significantly disturbs the balance between the horizontal wind and geopotential height. Thus, the difference of $\mathrm{R}$ between GCM and GCMbc can indicate the impact of bias correction on the dependency between wind and geopotential height. For comparison, we also calculated R for the ERA5 data.

The vertical profile of global mean $\mathrm{R}$ in GCMbc is very close to that in GCM and both show greater R than the ERA5 (Fig. 6). In the low latitudes, the bias correction leads to a decrease in geostrophic deviation because the GCM biases are corrected based on ERA5 and the geostrophic deviation is smaller in ERA5 than GCM (Fig. 6b). In the mid to high latitudes Northern Hemisphere, bias correction causes moderate but significant increases in $\mathrm{R}$ (less than 0.02). In East Asia, the comparison of GCMbc with GCM indicates that bias correction also leads to significant increases in R. However the difference of $\mathrm{R}$ between GCMbc and ERA5 are less significant below $300 \mathrm{hPa}$ (Fig. 6e). In the Northwest Pacific, bias correction has minor impacts on the intervariable dependency characterized by a less significant difference of $\mathrm{R}$ between the GCMbc and GCM (ERA5). Overall, bias correction does disturb the intervariable dependency to a certain extent. The geostrophic wind deviation can increase by approximately $20 \%$ in the mid and high latitudes of the Northern Hemisphere. Globally, only $10 \%$ of the area shows significant differences in R between the GCM and GCMbc. The disturbance of intervariable dependency induced by bias correction may affect the dynamical downscaling simulation to a certain extent. However, the impacts are expected to be small for a long-term simulation since the imbalance only appears in the initial and lateral boundary conditions of $\mathrm{RCM}^{20}$. In contrast, the bias correction-induced imbalance in GCM could significantly affect RCM simulation if nudging was employed during the integration of $\mathrm{RCM}$. In this case, one may consider reducing the strength of nudging ${ }^{20}$. 


\section{Usage Notes}

300 The China Science Data Bank provides the open-access data presented in this article, with a DOI (http://www.dx.doi.org/10.11922/sciencedb.00487). The NetCDF data was compressed variables. We provide a FORTRAN code to covert these compressed NetCDF files to WRF intermediate files (supplementary file). In addition to FORTRAN, a lot of software are available to manipulating or displaying NetCDF data, e.g., CDO, NCO, NCL, Python, Ncview, GrADS. More software can be found at https://www.unidata.ucar.edu/software/netcdf/software.html. The data provided here can be used to generate the lateral and underlying condition of RCM.

Besides, RCMs also need the surface air temperature, soil temperature, soil moisture as initial conditions. In terms of long-term climate projection, the bias correction for the initial condition would be less necessary. As the spin-up time of atmospheric variables is generally less than a month. The deep soil temperature and moisture do need a much longer time to spin up. Users can generate these data through an offline simulation of the land surface model driven by atmospheric forcing.

\section{Code Availability}

The code used to produce the bias-corrected global CMIP6 data is publicly available (supplementary file). The code consists of an NCL (version 6.6.2) script to compute non-linear trends and a few CDO (version 1.7.0) scripts to regrid data and correct CMIP6 data biases.

\section{Acknowledgements}

We acknowledge the World Climate Research Programme's Working Group on Coupled Modelling, which is responsible for CMIP, and we thank the climate modeling groups for producing and making available their model output. ERA5 Reanalysis data was provided by the European Centre for Medium-Range Weather Forecasts at the website https://www.ecmwf.int/en/forecasts/datasets/reanalysis-datasets/era5. ZX is supported jointly by the National Key Research and Development Program of China (2018YFA0606004) and National Natural Science Foundation of China (42075170). YH is supported jointly by the National Key Research and Development Program of China (2017YFA0603803) and National Science Foundation of China (41675105). CYT is supported by the Chinese University Direct Grant (No. 4053331).

\section{Author contributions}

ZX developed the GCM bias correction method and processed the CMIP6 data. ZX and YH perform the validation of bias corrected data against reanalysis data. All co-authors contributed to writing and commented on the manuscript.

\section{Competing interests}

The authors declare that they have no conflict of interest. 


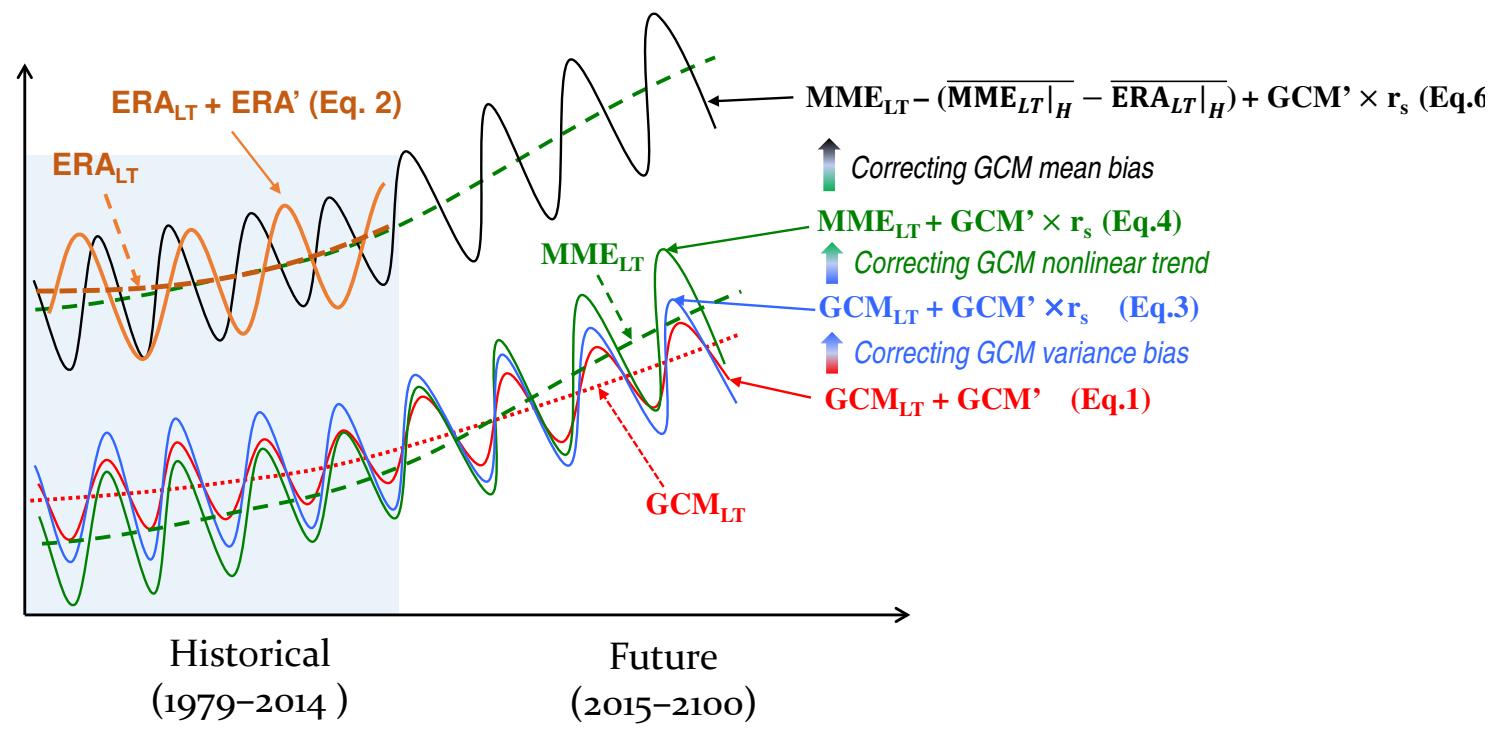

Fig. 1 Schematic chart for the process of GCM bias corrections 
(a) 600-hPa air temperature (T600)

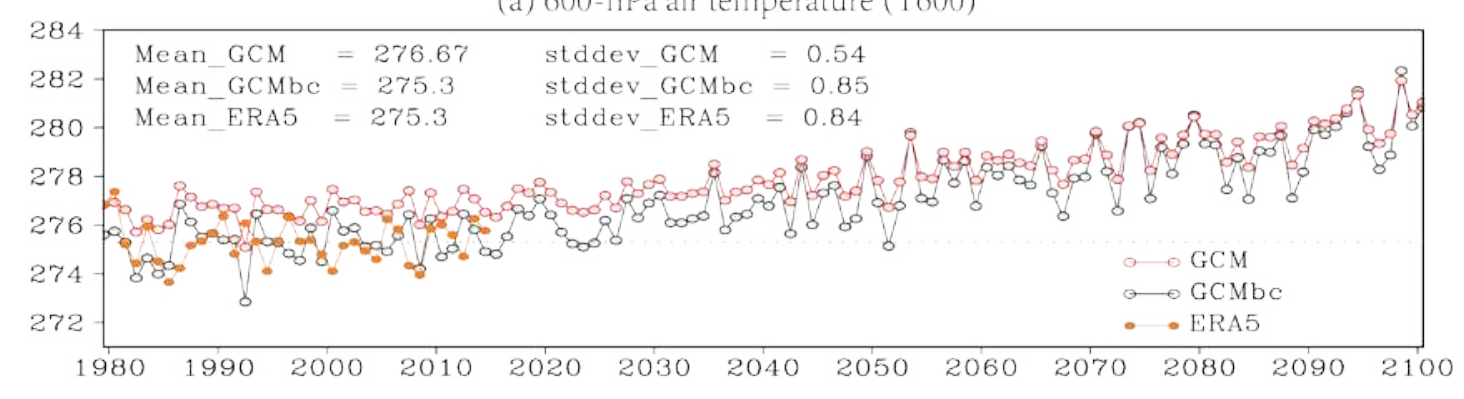

(b) frequency of T600 in July 1979-2014 historacal

(c) frequency of T600 in July 2015-2100 SSP585
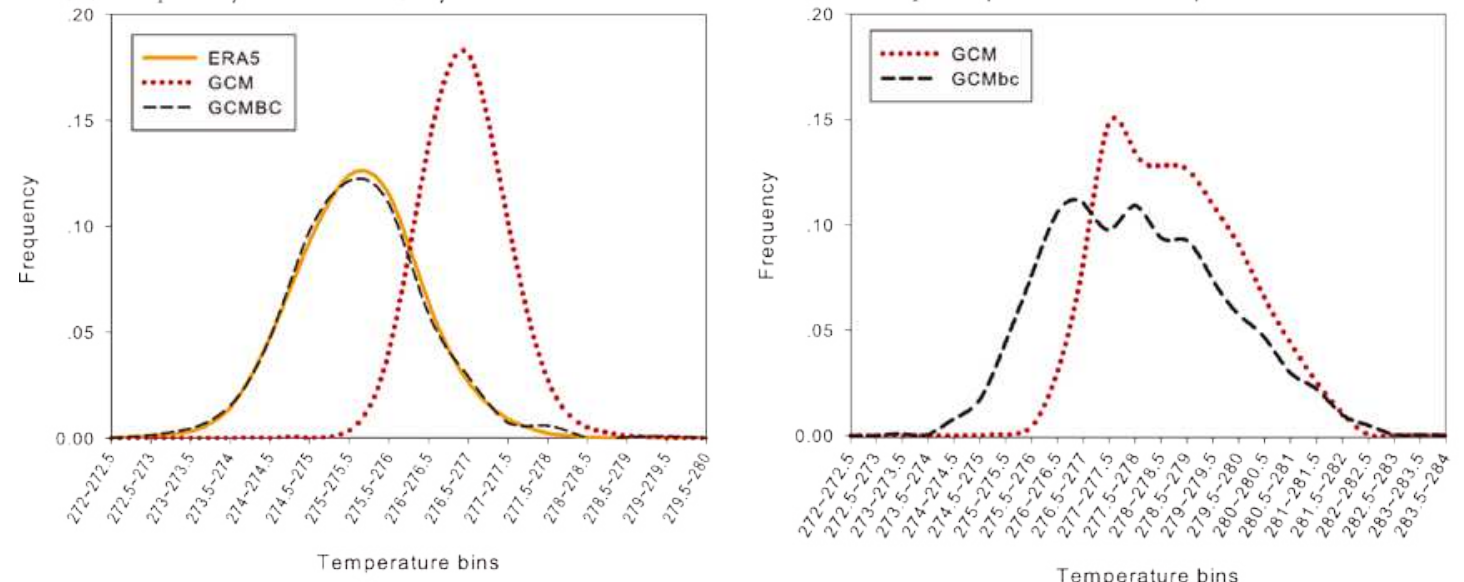

Fig. 2 Comparison of the original and bias-corrected data GCM data (GCMbc) with ERA5 during the historical (1979-2014) period and SSP585 scenarios (2015-2100). (a) 600-hPa air temperature (T600) in Northwest Pacific $\left(10^{\circ} \mathrm{N}, 135^{\circ} \mathrm{E}\right)$ at 00 UTC July 15 from 1979 to 2100. The 36-yr averaged (1979-2014) value and temporal standard deviation for each data are shown on the upper-left of (a). The frequency distribution of T600 in July during the period of (a) 1979-2014 and (b) 2015-2100 under SSP585 scenarios. The frequency (in percentage) is computed based on the instantaneous data at 00 UTC in July. There are 1116 days (31 day $\times 36$ year) and 2666 days ( 31 day $\times 86$ year) are included in the statistics for the historical and future periods, respectively. 


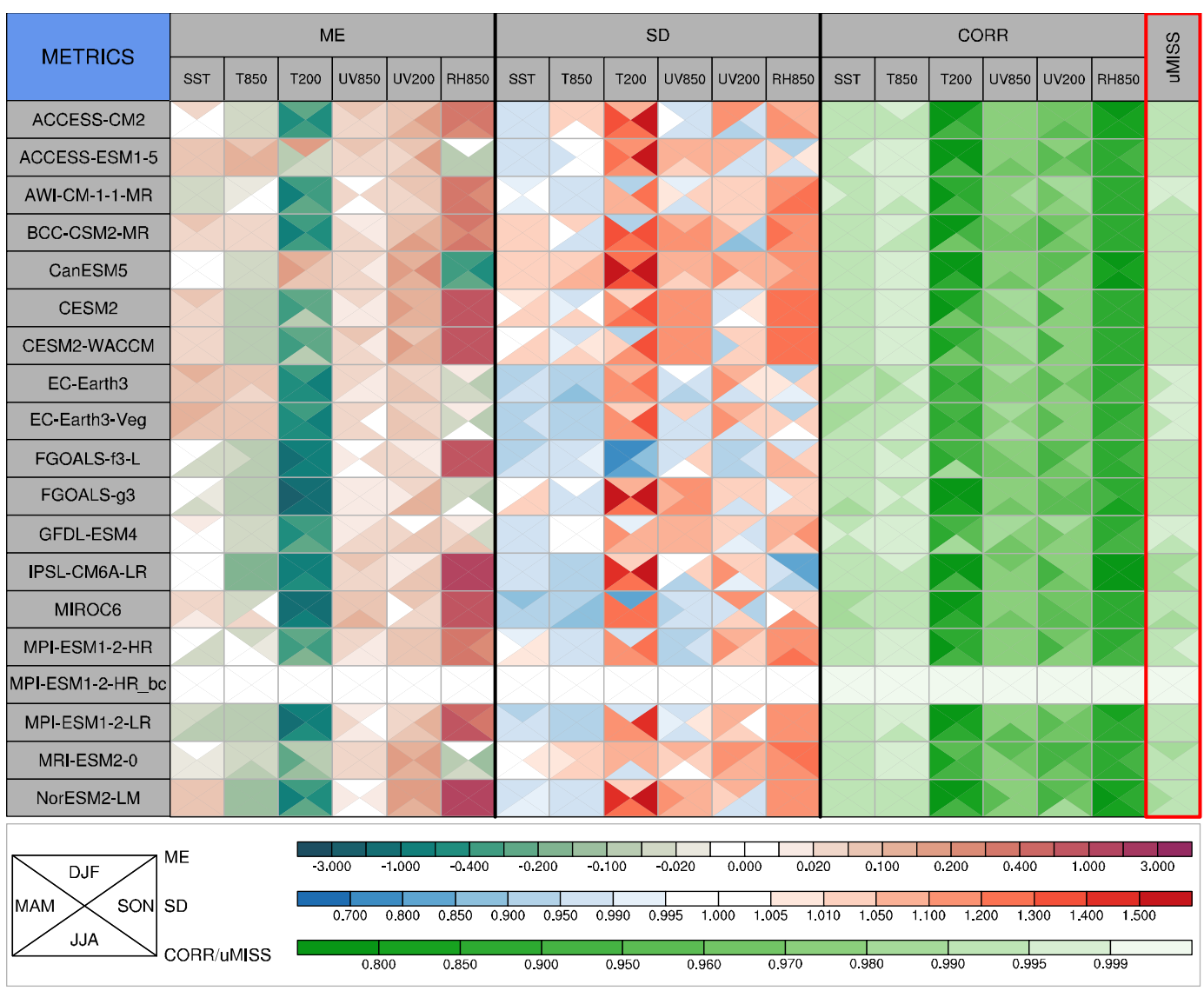

Fig. 3 Statistical metrics that measure the performance of CMIP6 models in simulating climatological mean (1979-2014) of multiple variables. SST: sea surface temperature, T850: 850-hPa air temperature, UV850: 850-hPa vector wind, RH850: 850-hPa relative humidity, T200: 200-hPa air temperature, UV200: 200-hPa vector wind in the global. ME, SD, and CORR are the mean error, spatial standard deviation, and correlation coefficient of the climatological mean field, respectively. uMISS is the uncentered multivariable integrated skill score that summarizes the overall performance of a model in simulating multiple variables. All statistics are normalized by dividing the observed standard deviation of the corresponding variable. All models are evaluated against ERA5. Lighter color represents better model performance. MPI-ESM1-2-HR_bc is the bias-corrected GCM data. 
(a) SST ERA5

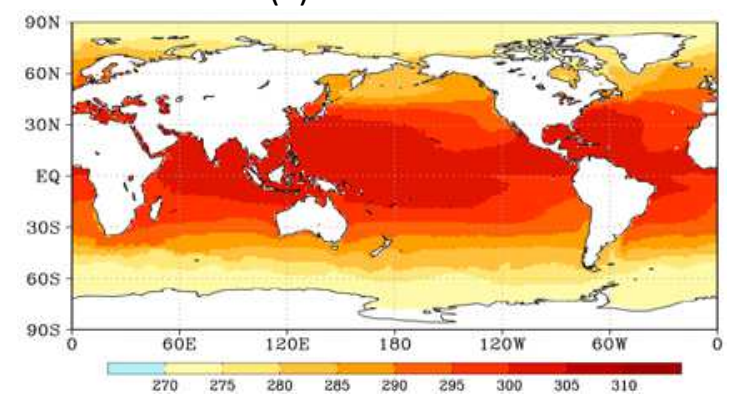

(c) SST GCM-ERA5

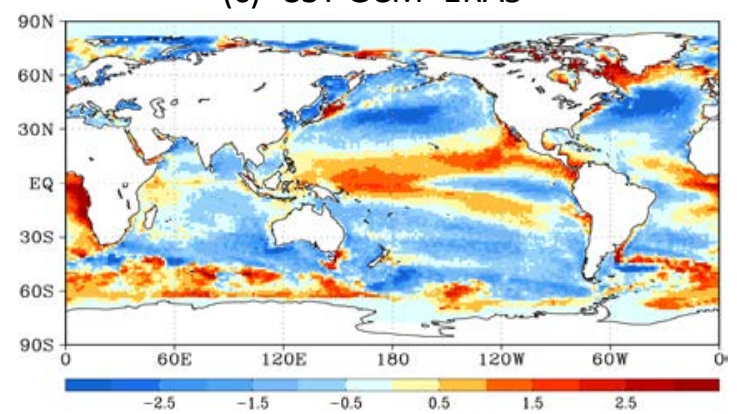

(e) SST GCMbc-ERA5

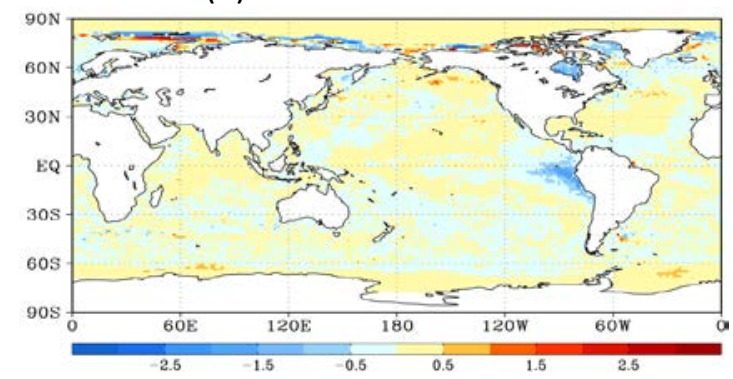

(b) Wind speed ERA5

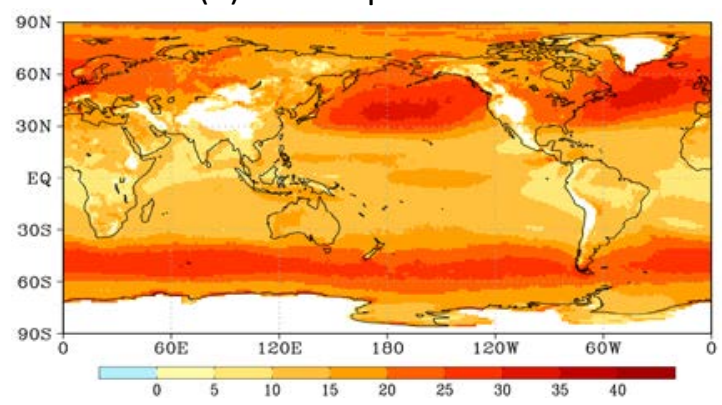

(d) Wind speed GCM-ERA5

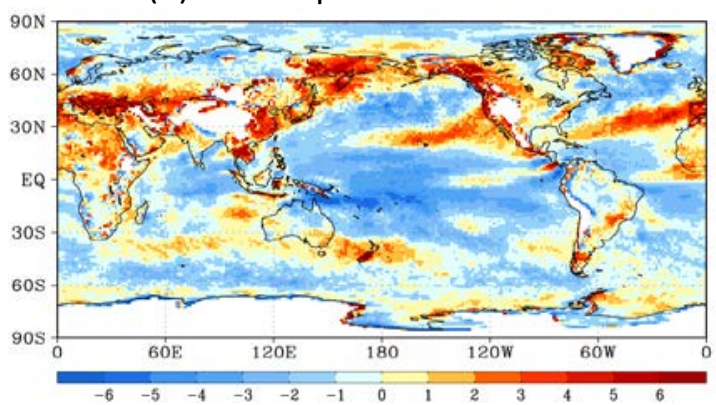

(f) Wind speed GCMbc-ERA5

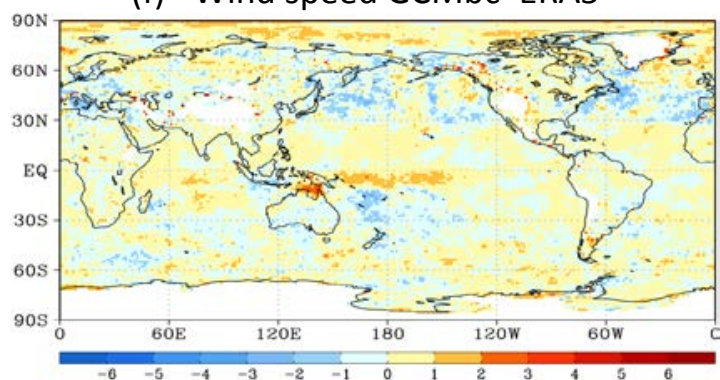

Fig. 4 Comparison of the 95th percentile of daily SST $\left({ }^{\circ} \mathrm{C}\right)$ and $850-\mathrm{hPa}$ wind speed wind $\left(\mathrm{m} \mathrm{s}^{-}\right.$ ${ }^{1}$ ) during July of 1979-2014 against ERA5. (a, b) ERA5, (c-f) difference between GCM (GCMbc) and ERA5. 
(a) Nonlinear trends of 850 -hPa air temperature

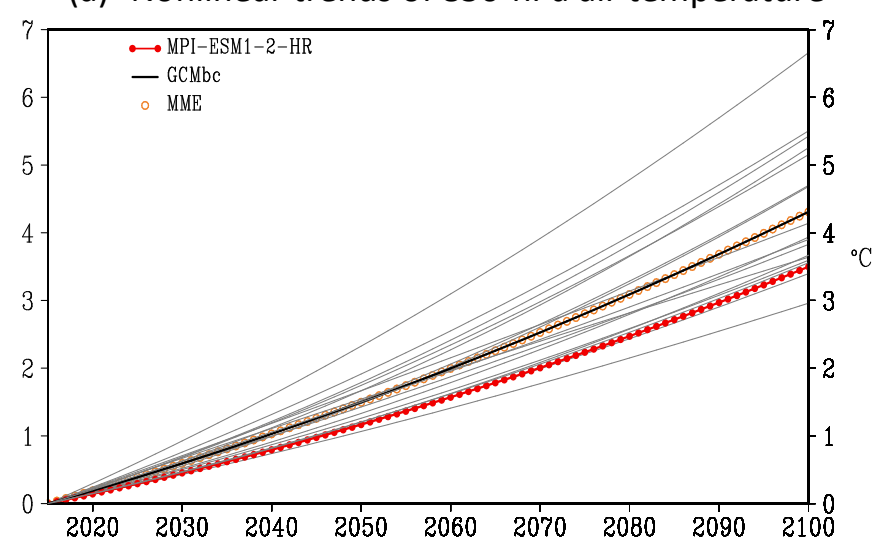

(b)RMSDs of nonlinear trend

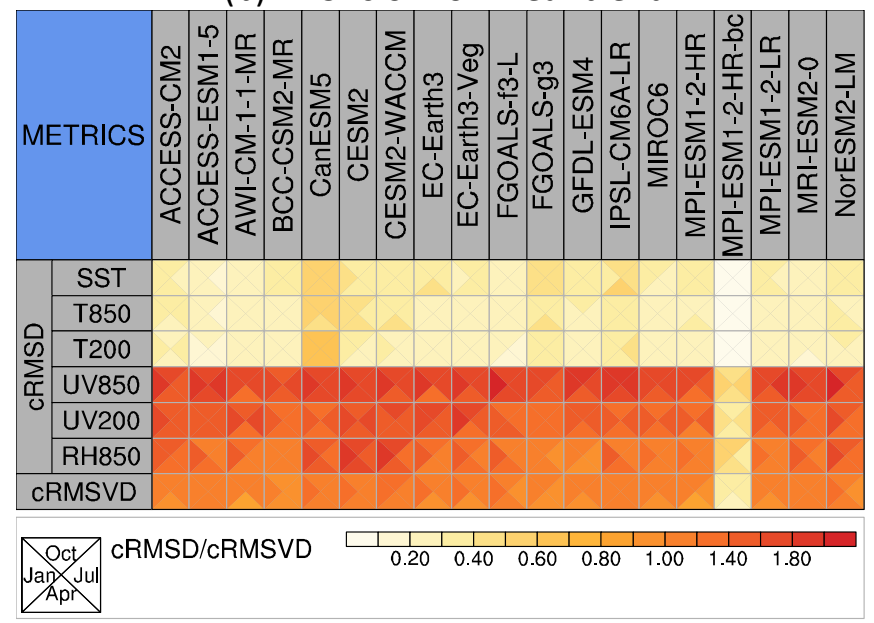

Fig. 5 Comparison of Nonlinear trend of various CMIP6 data against multi-model ensemble mean (MME) in July from 2015 to 2100 under SSP585 scenario. (a) Global 850-hPa air temperature. The orange open circle, red solid circles, and the thick black line represent the MME, MPI-ESM1-2-HR model the bias-corrected MPI-ESM1-2-HR model, respectively. The grey line indicates the other 17 CMIP6 models. The value of the non-linear trend in the year 2015 was subtracted from the original non-linear trend. (b) root-mean-square differences of the non-linear trends between the individual CMIP6 model and the MME. As in Fig. 3 the CRMSDs are also normalized by dividing the observed standard deviation of the corresponding variable. The CRMSVD represents the overall RMSD of all variables. The triangles in each grid cell represent the statistic in January, April, July, and October, respectively. 
(a) global

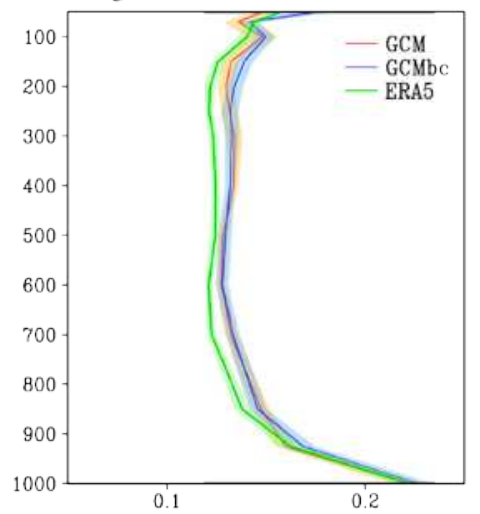

(d) High latitude $\mathrm{NH}$

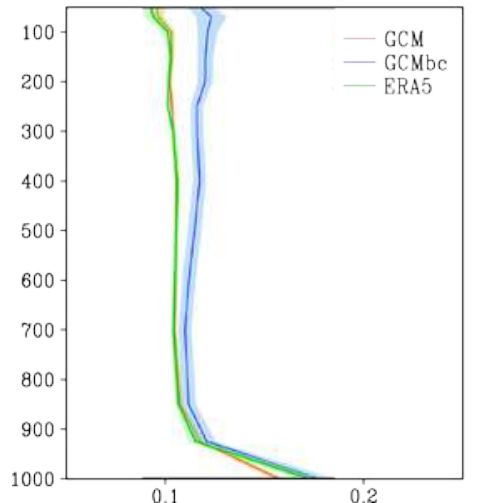

(b) Low latitude $\mathrm{NH}$

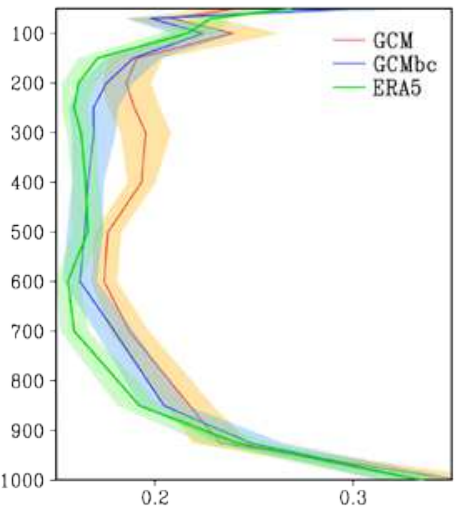

(e) East Asia

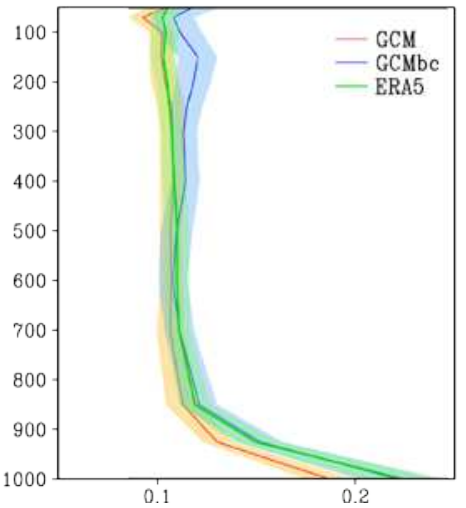

(c) Mid latitude $\mathrm{NH}$

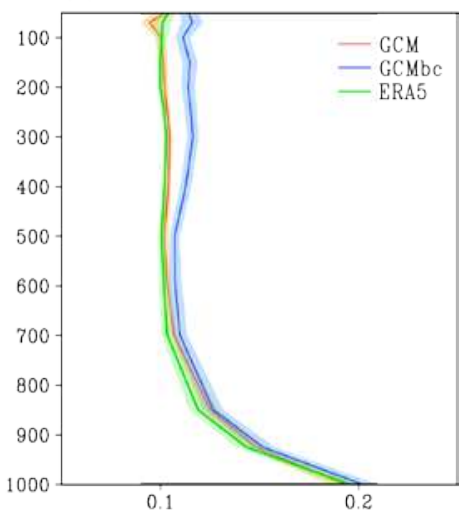

(f) Northwest Pacific

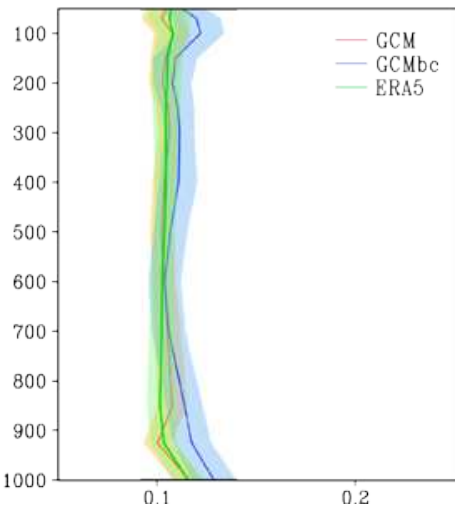

Fig. 6 The ratio (R) of ageostrophic wind speed to the real wind speed averaged over various regions in July 2014. The shading shows the one standard deviation. The ageostrophic wind and real wind are calculated using 6-hourly data in July 2014 . The area-mean R is computed in mid $\left(20^{\circ}-50^{\circ} \mathrm{N}, 0-358.75^{\circ} \mathrm{E}\right)$ and high latitudes $\left(50-90^{\circ} \mathrm{N}, 0-358.75^{\circ} \mathrm{E}\right)$ of Northern Hemisphere, East Asia $\left(10^{\circ}-55^{\circ} \mathrm{N}, 105^{\circ}-140^{\circ} \mathrm{E}\right)$, and Northwest Pacific $\left(10^{\circ}-40^{\circ} \mathrm{N}, 135^{\circ} \mathrm{E}-\right.$ $\left.180^{\circ}\right)$. The grid cells with wind speed less than $2 \mathrm{~m} \mathrm{~s}^{-1}$ were excluded from the statistics. 


\section{Figure Legends}

Fig. 2 Schematic chart for the process of GCM bias corrections

Fig. 2 Comparison of the original and bias-corrected data GCM data (GCMbc) with ERA5 during the historical (1979-2014) period and SSP585 scenarios (2015-2100). (a) 600-hPa air temperature (T600) in Northwest Pacific $\left(10^{\circ} \mathrm{N}, 135^{\circ} \mathrm{E}\right)$ at 00 UTC July 15 from 1979 to 2100. The 36-yr averaged (1979-2014) value and temporal standard deviation for each data are shown on the upper-left of (a). The frequency distribution of T600 in July during the period of (a) 1979-2014 and (b) 2015-2100 under SSP585 scenarios. The frequency (in percentage) is computed based on the instantaneous data at 00 UTC in July. There are 1116 days ( 31 day $\times 36$ year) and 2666 days ( 31 day $\times 86$ year) are included in the statistics for the historical and future periods, respectively.

Fig. 3 Statistical metrics that measure the performance of CMIP6 models in simulating climatological mean (1979-2014) of multiple variables. SST: sea surface temperature, T850: 850-hPa air temperature, UV850: 850-hPa vector wind, RH850: 850-hPa relative humidity, T200: 200-hPa air temperature, UV200: 200-hPa vector wind in the global. ME, SD, and CORR are the mean error, spatial standard deviation, and correlation coefficient of the climatological mean field, respectively. uMISS is the uncentered multivariable integrated skill score that summarizes the overall performance of a model in simulating multiple variables. All statistics are normalized by dividing the observed standard deviation of the corresponding variable. All models are evaluated against ERA5. Lighter color represents better model performance. MPI-ESM1-2-HR_bc is the bias-corrected GCM data.

Fig. 4 Comparison of the 95th percentile of daily SST $\left({ }^{\circ} \mathrm{C}\right)$ and $850-\mathrm{hPa}$ wind speed wind $\left(\mathrm{m} \mathrm{s}^{-}\right.$ $\left.{ }^{1}\right)$ during July of 1979-2014 against ERA5. (a, b) ERA5, (c-f) difference between GCM (GCMbc) and ERA5.

Fig. 5 Comparison of Nonlinear trend of various CMIP6 data against multi-model ensemble mean (MME) in July from 2015 to 2100 under SSP585 scenario. (a) Global 850-hPa air temperature. The orange open circle, red solid circles, and the thick black line represent the MME, MPI-ESM1-2-HR model the bias-corrected MPI-ESM1-2-HR model, respectively. The grey line indicates the other 17 CMIP6 models. The value of the non-linear trend in the year 2015 was subtracted from the original non-linear trend. (b) root-mean-square differences of the non-linear trends between the individual CMIP6 model and the MME. As in Fig. 3 the CRMSDs are also normalized by dividing the observed standard deviation of the corresponding variable. The CRMSVD represents the overall RMSD of all variables. The triangles in each grid cell represent the statistic in January, April, July, and October, respectively.

Fig. 6 The ratio $(R)$ of ageostrophic wind speed to the real wind speed averaged over various regions in July 2014. The shading shows the one standard deviation. The ageostrophic wind and real wind are calculated using 6-hourly data in July 2014 . The area-mean R is computed in mid $\left(20^{\circ}-50^{\circ} \mathrm{N}, 0-358.75^{\circ} \mathrm{E}\right)$ and high latitudes $\left(50-90^{\circ} \mathrm{N}, 0-358.75^{\circ} \mathrm{E}\right)$ of Northern Hemisphere, East Asia $\left(10^{\circ}-55^{\circ} \mathrm{N}, 105^{\circ}-140^{\circ} \mathrm{E}\right)$, and Northwest Pacific $\left(10^{\circ}-40^{\circ} \mathrm{N}, 135^{\circ} \mathrm{E}-\right.$ $\left.180^{\circ}\right)$. The grid cells with wind speed less than $2 \mathrm{~m} \mathrm{~s}^{-1}$ were excluded from the statistics. 


\section{Tables}

Table 1. CMIP6 models used in this study

\begin{tabular}{|c|c|c|c|}
\hline No. & Model & Institution & Grid spacing \\
\hline 1 & ACCESS-CM2 & $\begin{array}{l}\text { Commonwealth Scientific and Industrial Research } \\
\text { Organisation, and Australian Research Council } \\
\text { Centre of Excellence for Climate System Science } \\
\text { (Australia) }\end{array}$ & $\sim 1.875^{\circ} \times 1.25^{\circ}$ \\
\hline 2 & ACCESS-ESM1-5 & $\begin{array}{l}\text { Commonwealth Scientific and Industrial Research } \\
\text { Organisation (Australia) }\end{array}$ & $\sim 1.875^{\circ} \times 1.25^{\circ}$ \\
\hline 3 & CanESM5 & $\begin{array}{l}\text { Canadian Centre for Climate Modelling and Analysis, } \\
\text { Environment and Climate Change (Canada) }\end{array}$ & $\sim 2.81^{\circ} \times 2.81^{\circ}$ \\
\hline 4 & BCC-CSM2-MR & Beijing Climate Center (China) & $\sim 1.125^{\circ} \times 1.125^{\circ}$ \\
\hline 5 & FGOALS-f3-L & $\begin{array}{l}\text { Institute of Atmospheric Physics, Chinese Academy } \\
\text { of Sciences (China) }\end{array}$ & $\sim 1.25^{\circ} \times 1^{\circ}$ \\
\hline 6 & FGOALS-g3 & $\begin{array}{l}\text { Institute of Atmospheric Physics, Chinese Academy } \\
\text { of Sciences (China) }\end{array}$ & $\sim 2^{\circ} \times 2.25^{\circ}$ \\
\hline 7 & EC-Earth3 & $\begin{array}{l}\text { European community (including multiple institutes } \\
\text { from Spain, Italy, Denmark, Germany, Ireland, } \\
\text { Portugal, Netherlands, Sweden, Norway, UK, } \\
\text { Belgium, and Finland) }\end{array}$ & $\sim 0.70^{\circ} \times 0.70^{\circ}$ \\
\hline 8 & EC-Earth3-Veg & European community & $\sim 0.70^{\circ} \times 0.70^{\circ}$ \\
\hline 9 & IPSL-CM6A-LR & Institute Pierre Simon Laplace (France) & $\sim 2.5^{\circ} \times 1.27^{\circ}$ \\
\hline 10 & $\begin{array}{l}\text { AWI-CM-1-1- } \\
\text { MR }\end{array}$ & $\begin{array}{l}\text { Alfred Wegener Institute, Helmholtz Centre for } \\
\text { Polar and Marine Research (Germany) }\end{array}$ & $\sim 0.94^{\circ} \times 0.94^{\circ}$ \\
\hline 11 & $\begin{array}{l}\text { MPI-ESM1-2- } \\
\text { HR }\end{array}$ & $\begin{array}{l}\text { Max Planck Institute for Meteorology, and } \\
\text { Deutsches Klimarechenzentrum (Germany) }\end{array}$ & $\sim 0.94^{\circ} \times$ \\
\hline 12 & MPI-ESM1-2-LR & $\begin{array}{l}\text { Max Planck Institute for Meteorology, and Alfred } \\
\text { Wegener Institute, Helmholtz Centre for Polar and } \\
\text { Marine Research (Germany) }\end{array}$ & 1.8 \\
\hline 13 & MIROC6 & $\begin{array}{l}\text { Japan Agency for Marine-Earth Science and } \\
\text { Technology, Atmosphere and Ocean Research } \\
\text { Institute, National Institute for Environmental } \\
\text { Studies, and RIKEN Center for Computational } \\
\text { Science (Japan) }\end{array}$ & $\sim 1.41^{\circ} \times 1.41^{\circ}$ \\
\hline 14 & MRI-ESM2-0 & Meteorological Research Institute (Japan) & $\sim 1.125^{\circ} \times 1.125^{\circ}$ \\
\hline 15 & NorESM2-LM & $\begin{array}{l}\text { Center for International Climate and Environmental } \\
\text { Research, Norwegian Meteorological Institute, } \\
\text { Nansen Environmental and Remote Sensing Center, } \\
\text { NERSC, Norwegian Institute for Air Research, } \\
\text { University of Bergen, University of Oslo, Uni } \\
\text { Research (Norway) }\end{array}$ & $\sim 2.5^{\circ} \times 1.89^{\circ}$ \\
\hline 16 & CESM2 & $\begin{array}{l}\text { National Center for Atmospheric Research, Climate } \\
\text { and Global Dynamics Laboratory (USA) }\end{array}$ & $\sim 1.25^{\circ} \times 0.94^{\circ}$ \\
\hline 17 & $\begin{array}{l}\text { CESM2- } \\
\text { WACCM }\end{array}$ & $\begin{array}{l}\text { National Center for Atmospheric Research, Climate } \\
\text { and Global Dynamics Laboratory (USA) }\end{array}$ & $\sim 1.25^{\circ} \times 0.94^{\circ}$ \\
\hline 18 & GFDL-ESM4 & Geophysical Fluid Dynamics Laboratory (USA) & \\
\hline
\end{tabular}


408

Table 2 The bias-corrected variables

\begin{tabular}{|l|l|l|c|c|c|}
\hline Variables & Acronym & $\begin{array}{c}\text { Vertical } \\
\text { levels }\end{array}$ & $\begin{array}{c}\text { Historial } \\
\text { 1979-2014 }\end{array}$ & $\begin{array}{c}\text { SSP245 } \\
\text { 2015-2100 }\end{array}$ & $\begin{array}{c}\text { SSP585 } \\
\text { 2015-2100 }\end{array}$ \\
\hline Sea surface temperature & tos & 1 & $\sqrt{ }$ & $\sqrt{ }$ & $\sqrt{ }$ \\
\hline Sea level pressure & psl & 1 & $\sqrt{ }$ & $\sqrt{ }$ & $\sqrt{ }$ \\
\hline Surface pressure & ps & 1 & $\sqrt{ }$ & $\sqrt{ }$ & $\sqrt{ }$ \\
\hline Air temperature & ta & 14 & $\sqrt{ }$ & $\sqrt{ }$ & $\sqrt{ }$ \\
\hline Zonal wind & ua & 14 & $\sqrt{ }$ & $\sqrt{ }$ & $\sqrt{ }$ \\
\hline Meridional wind & va & 14 & $\sqrt{ }$ & $\sqrt{ }$ & $\sqrt{ }$ \\
\hline relative humidity & hur & 14 & $\sqrt{ }$ & $\sqrt{ }$ & $\sqrt{ }$ \\
\hline Geopotential height & zg & 14 & $\sqrt{ }$ & &
\end{tabular}

409

410 


\section{References}

412

413

414

415

416

417

418

419

420

421

422

423

424

425

426

427

428

429

430

431

432

433

434

435

436

437

438

439

440

441

442

443

444

445

446

447

448

449

450

451

452

453

454

455

456

457

458

459

460

461

462

1. Marchi, M., Castellanos-Acuña, D., Hamann, A., Wang, T. Ray D., \& Menzel, A. ClimateEU, scale-free climate normals, historical time series, and future projections for Europe. Scientific Data, 7, 428. https://doi.org/10.1038/s41597-020-00763-0 (2020).

2. Navarro-Racines, C., Tarapues, J., Thornton, P., Jarvis A. \& Ramirez-Villegas, J. Highresolution and bias-corrected CMIP5 projections for climate change impact assessments. Scientific Data 7, 7, https://doi.org/10.1038/s41597-019-0343-8 (2020).

3. Wilby, R. L. et al. Statistical downscaling of general circulation model output: $A$ comparison of methods. Water Resources Research, 34(11), 2995-3008 (1998).

4. Fan, L., Chen, D., Fu, C. \& Yan, Z. Statistical downscaling of summer temperature extremes in northern China. Adv. Atmos. Sci. 30(4), 1085-1095, doi: 10.1007/s00376-012-2057-0 (2013).

5. Giorgi, F., Brodeur, C. S. \& Bates, G. T. Regional climate change scenarios over the United States produced with a nested regional climate model. J. Climate, 7, 357-399, (1994).

6. Giorgi, F., Jones, G. \& Asrar, G. R. Addressing climate information needs at the regional level: The CORDEX framework, WMO Bull, 58(3), 175-183 (2009).

7. Fu C. et al. Regional Climate Model Intercomparison Project for Asia. Bull. Amer. Meteorol. Soc. 86, 257-266 (2005).

8. Gutowski, W.J. The ongoing need for high-resolution regional climate models: Process understanding and stakeholder information. Bull. Amer. Meteorol. Soc. 101(5), E664E683; DOI: https://doi.org/10.1175/BAMS-D-19-0113.1 (2020).

9. Walton, D., Sun, F., Hall, A. \& Capps. C. A hybrid dynamical-statistical downscaling technique. Part I: Development and validation of the technique. J. Climate, 28, 4597-4617 (2015).

10.Sun, F, Walton, D., \& Hall, A. A Hybrid Dynamical-Statistical Downscaling Technique, Part II: End-of-Century Warming Projections Predict a New Climate State in the Los Angeles Region. J. Climate, 28, 4618-4636 (2015).

11.Giorgi, F. \& Mearns, L. O. Introduction to special section: Regional climate modeling revisited. J. Geophys. Res. 104, 6335-6352, doi:10.1029/98JD02072 (1999).

12.Bukovsky, M. S. \& Karoly, D. J. A regional modeling study of climate change impacts on warm-season precipitation in the central United States. J. Climate, 24, 1985-2002 (2011).

13.Tang, J. P., et al. Building Asian climate change scenario by multiregional climate models ensemble. Part I: Surface air temperature. Int. J. Climatol., 36, 4241-4252 (2016).

14.Wu, W. \& Lynch, A. H. Response of the seasonal carbon cycle in high latitudes to climate anomalies. J. Geophys. Res. 105 (D18), 22897-22908 (2000).

15.Sato, T., Kimura, F. \& Kitoh, A. Projection of global warming onto regional precipitation over Mongolia using a regional climate model. J. Hydrol., 333, 144-154 (2007).

16.Xu, Z. F. \& Yang, Z.-L. An Improved Dynamical Downscaling Method with GCM Bias Corrections and Its Validation with 30 Years of Climate Simulations. J. Climate, 25, 62716286 (2012).

17.Holland, G. J., Done, J., Bruyere, C., Cooper, C. \& Suzuki, A. Model investigations of the effects of climate variability and change on futureGulf of Mexico tropical cyclone activity. Proc. Offshore Technology Conf., Houston, TX, ASCE, OTC 20690, (2010).

18.Done, J. M., Holland, G. J., Bruyère, C. L., Leung, L. R. \& Suzuki-Parker, A. Modeling highimpact weather and climate: Lessons from a tropical cyclone perspective. Clim. Change, 129, 381-395 (2015).

19.Bruyère, C. L., Done, J. M., Holland, G. J. \& Fredrick, S. Bias corrections of global models for regional climate simulations of high-impact weather. Clim. Dyn., 43, 1847-1856 (2014).

20.Xu, Z. F. \& Yang, Z.-L.: A new dynamical downscaling approach with GCM bias corrections and spectral nudging. J. Geophys. Res. Atmos., doi:10.1002/2014JD022958 (2015).

21.Colette, A., Vautard, R. \& Vrac M. Regional climate downscaling with prior statistical correction of the global climate forcing. Geophys. Res. Lett., 39, L13707 (2012). 
463

464

465

466

467

468

469

470

471

472

473

474

475

476

477

478

479

480

481

482

483

484

485

486

487

488

489

490

491

492

493

494

495

496

497

498

499

500

501

502

503

504

505

506

507

508

509

510

511

512

22.Rocheta, E., Evans, J. P. \& Sharma, A. Can Bias Correction of Regional Climate Model Lateral Boundary Conditions Improve Low-Frequency Rainfall Variability? J. Clim., 30, 9785-9806 (2017).

23.Dai, A. G., Rasmussen, R. M., Ikeda, K. \& Liu, C. H. A new approach to construct representative future forcing data for dynamic downscaling. Clim. Dyn., doi: 10.1007/s00382-017-3708-8 (2017).

24.Xu, Z. F., Han, Y. \& Yang, Z.-L.: Dynamical downscaling of regional climate: A review of methods and limitations. Science China Earth Sciences, 129. https://doi.org/10.1007/s11430-018-9261-5 (2019).

25.Adachi, S. A. \& Tomita, H. Methodology of the constraint condition in dynamical downscaling for regional climate evaluation: A review. J. Geosphys. Res. Atmos., 125(11), DOI:10.1029/2019JD032166 (2020).

26. White, R. H. \& Toumi, R. The limitations of bias correcting regional climate model inputs. Geophys. Res. Lett., 40, 2907-2912, doi:10.1002/grl.50612 (2013).

27.IPCC. Climate Change 2013. The Physical Science Basis. Contribution of Working Group I to the Fifth Assessment Report of the Intergovernmental Panel on Climate Change. In: Stocker T F, Qin D, Plattner G K, Tignor M, Allen S K, Boschung J, Nauels A, Xia Y, Bex V, Midgley P M, eds. Cambridge: Cambridge University Press. 1535 (2013).

28.Latif, M. Uncertainty in climate change projections. Journal of Geochemical Exploration, 110, 1-7, (2011).

29.Eyring, V. et al. Overview of the Coupled Model Intercomparison Project Phase 6 (CMIP6) experimental design and organization. Geoscientific Model Development, 9(5), 1937-1958. https://doi.org/10.5194/gmd-9-1937-2016 (2016).

30.Huang, F., Xu, Z., Guo, W.: Evaluating vector winds in the Asian-Australian monsoon region simulated by 37 CMIP5 models. Clim. Dyn., 53: 491. https://doi.org/10.1007/s00382-018-4599-z, 2019.

31.Richter, I. \& Tokinaga, H. An overview of the performance of CMIP6 models in the tropical Atlantic: mean state, variability, and remote impacts. Clim. Dyn., 55, 2579-2601 (2020).

32. Mauritsen, T., et al. Developments in the MPI-M Earth System Model version 1.2 (MPIESM1.2) and its response to increasing $\mathrm{CO}_{2}$. Journal of Advances in Modeling Earth Systems, 11, 998-1038 (2019).

33.Müller, W. A., et al.: A high-resolution version of the Max Planck Institute Earth System Model MPI-ESM1.2-HR. Journal of Advances in Modeling Earth Systems, 10, 1383-1413 (2018).

34.Krismer, T. R., Giorgetta, M. A. \& Esch, M.: Seasonal aspects of the quasi-biennial oscillation in MPI-ESM and ERA-40. Journal of Advances in Modeling Earth Systems, 5, 406-421, https://doi.org/10.1002/jame.20024 (2013).

35. Hersbach, H., et al. The ERA5 global reanalysis. Quarterly Journal of the Royal Meteorological Society, 146, 1999-2049 (2020).

36.Wu, Z. \& Huang, N. E. Ensemble Empirical Mode Decomposition: a noise-assisted data analysis method. Advances in Adaptive Data Analysis, 1, 1-41 (2009).

37. Hoffmann, P., Katzfey, J. J., McGregor, J. L. \& Thatcher, M. Bias and variance correction of sea surface temperatures used for dynamical downscaling, J. Geophys. Res. Atmos., 121, doi:10.1002/2016JD025383 (2016).

38.Xu, Z. F., Hou, Z. L., Han, Y. \& Guo, W. D.: A diagram for evaluating multiple aspects of model performance in simulating vector fields, Geosci. Model Dev., doi:10.5194/gmd2016-172, (2016).

39.Xu, Z. F., Han, Y. \& Fu, C.: Multivariable Integrated Evaluation of Model Performance with the Vector Field Evaluation Diagram. Geosci. Model Dev., 10, 3805-3820, https://doi.org/10.5194/gmd-10-3805-2017 (2017). 
40.Zhang, M.-Z., Xu, Z. F., Han, Y. \& Guo, W. D. An improved multivariable integrated evaluation method and NCL code for multimodel intercomparison. Geosci. Model Dev. Diss. https://gmd.copernicus.org/preprints/gmd-2020-310/ (2020).

41.Xu, Z. F. Bias-corrected CMIP6 global dataset for dynamical downscaling of future climate, 1979-2100. V1. China Science

Data Bank. http://www.dx.doi.org/10.11922/sciencedb.00487 (2021).

42.Rocheta, E., Evans, J. P. \& Sharma, A. Correcting lateral boundary biases in regional climate modeling - the effect of the relaxation zone. Clim. Dyn. https://doi.org/10.1007/s00382-020-05393-1 (2020).

43. Huang, F., Xu, Z., Guo, W. The linkage between CMIP5 climate models' abilities to simulate precipitation and vector winds. Clim. Dyn., 54, 4953-4970 (2020).

44. Meyer, J. D. D. \& Jin, J. M. Bias correction of the CCSM4 for improved regional climate modeling of the North American monsoon. Clim. Dyn., 46, 2961-2976 (2015). 
Figures

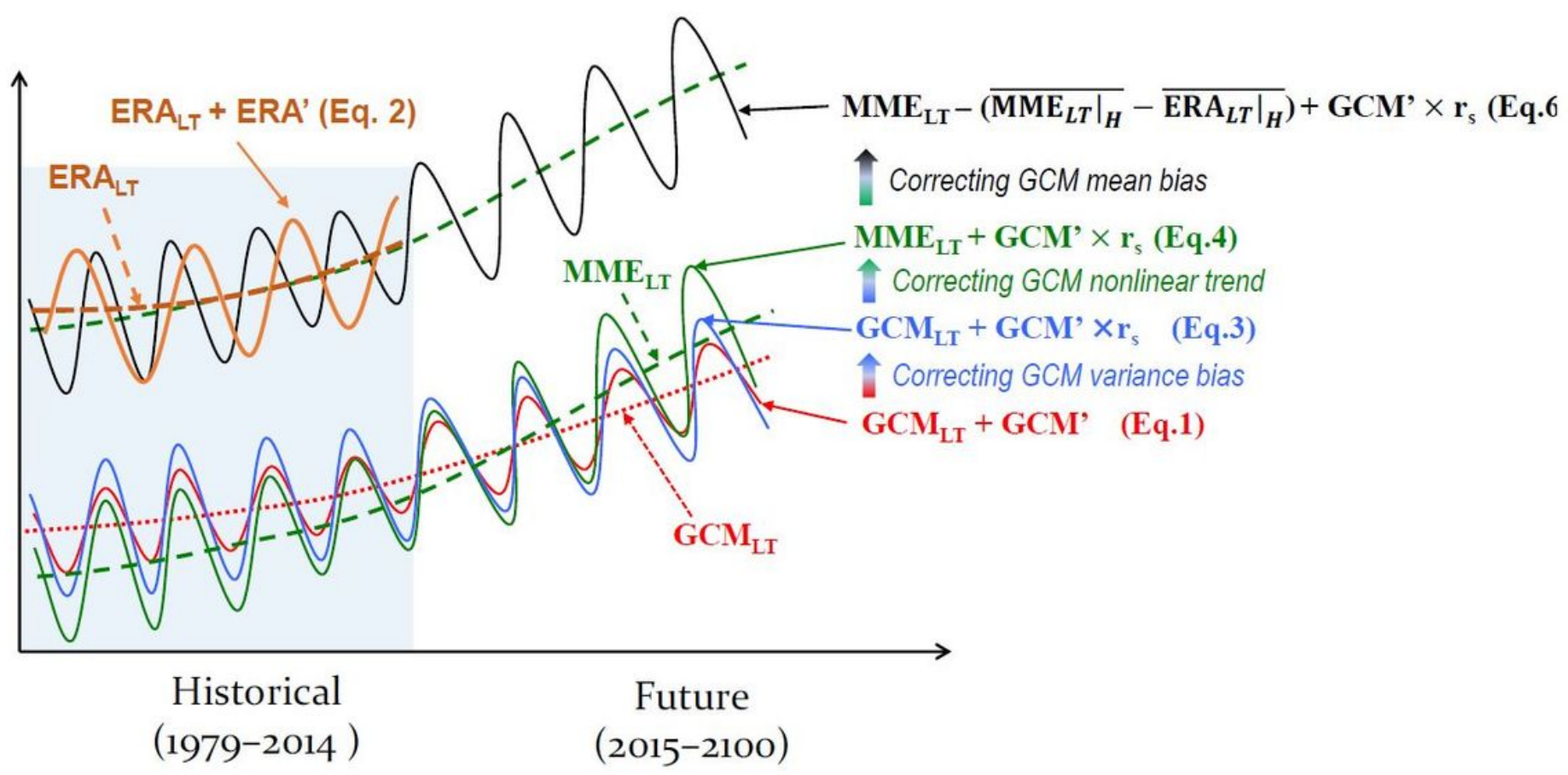

Figure 1

Schematic chart for the process of GCM bias corrections 
(a) 600-hPa air temperature (T600)

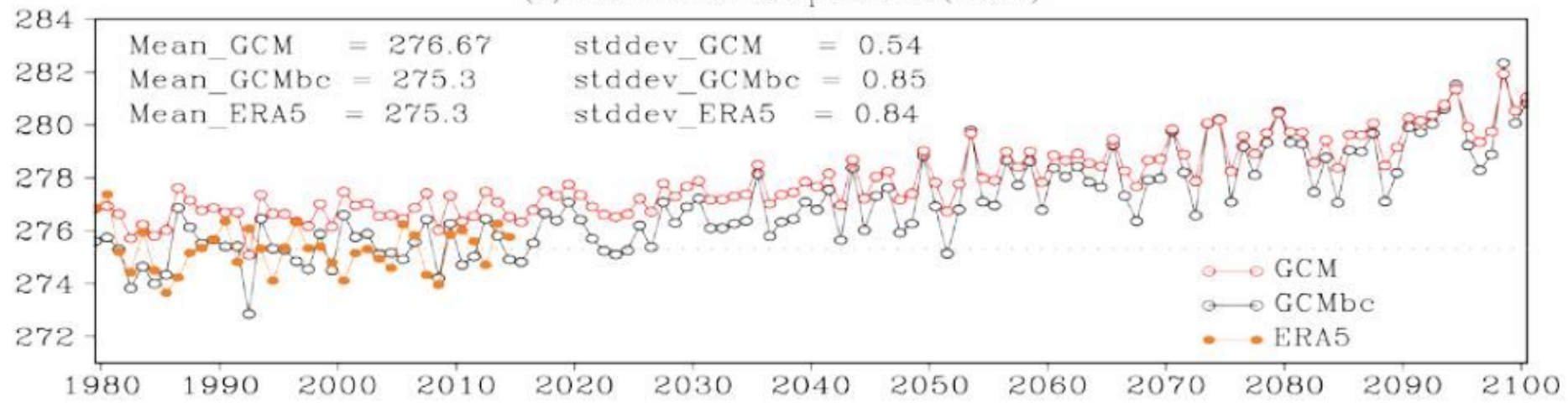

(b) frequency of T600 in July 1979-2014 historacal

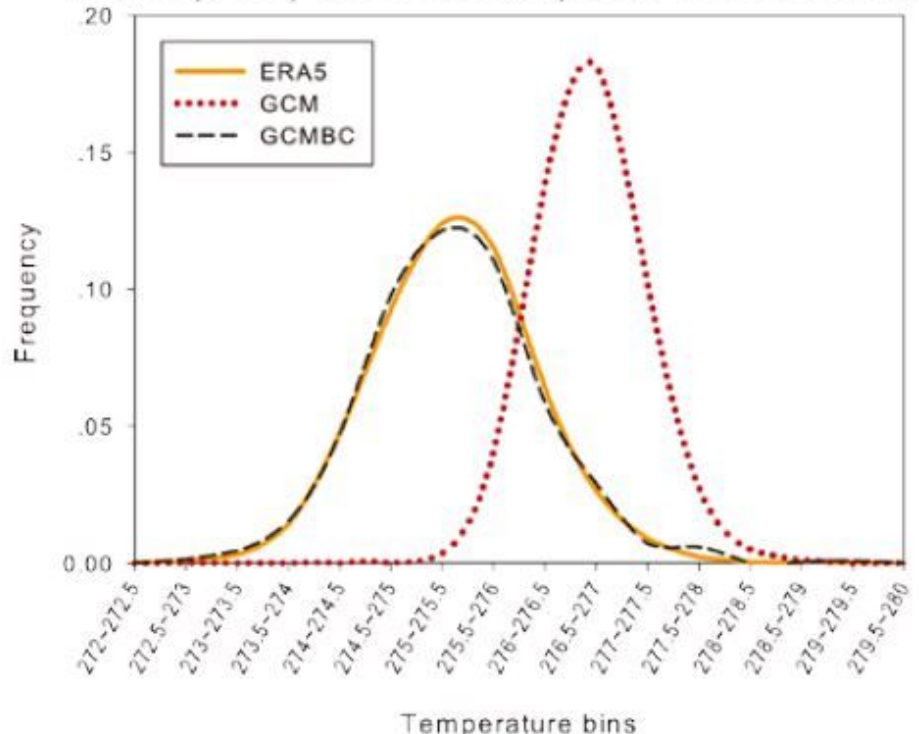

(c) frequency of T600 in July 2015-2100 SSP585

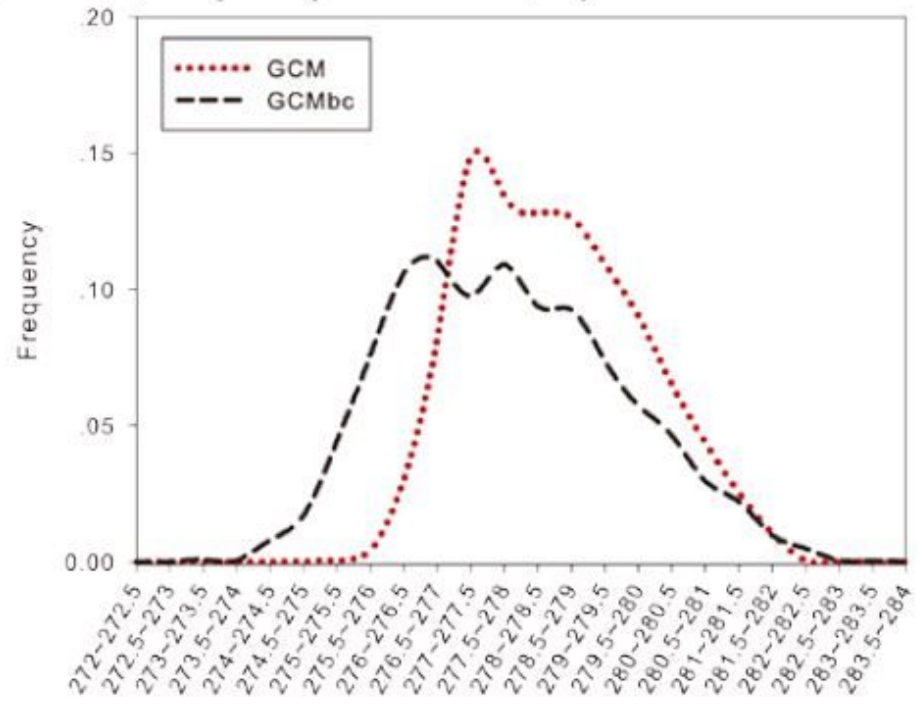

Temperature bins

\section{Figure 2}

Comparison of the original and bias-corrected data GCM data (GCMbc) with ERA5 during the historical (1979-2014) period and SSP585 scenarios (2015-2100). (a) 600-hPa air temperature (T600) in Northwest Pacific $\left(10^{\circ} \mathrm{N}, 135^{\circ} \mathrm{E}\right)$ at 00 UTC July 15 from 1979 to 2100 . The 36-yr averaged (1979-2014) value and temporal standard deviation for each data are shown on the upper-left of (a). The frequency distribution of T600 in July during the period of (a) 1979-2014 and (b) 2015-2100 under SSP585 scenarios. The frequency (in percentage) is computed based on the instantaneous data at 00 UTC in July. There are 1116 days ( 31 day $\times 36$ year) and 2666 days ( 31 day $\times 86$ year) are included in the statistics for the historical and future periods, respectively. 


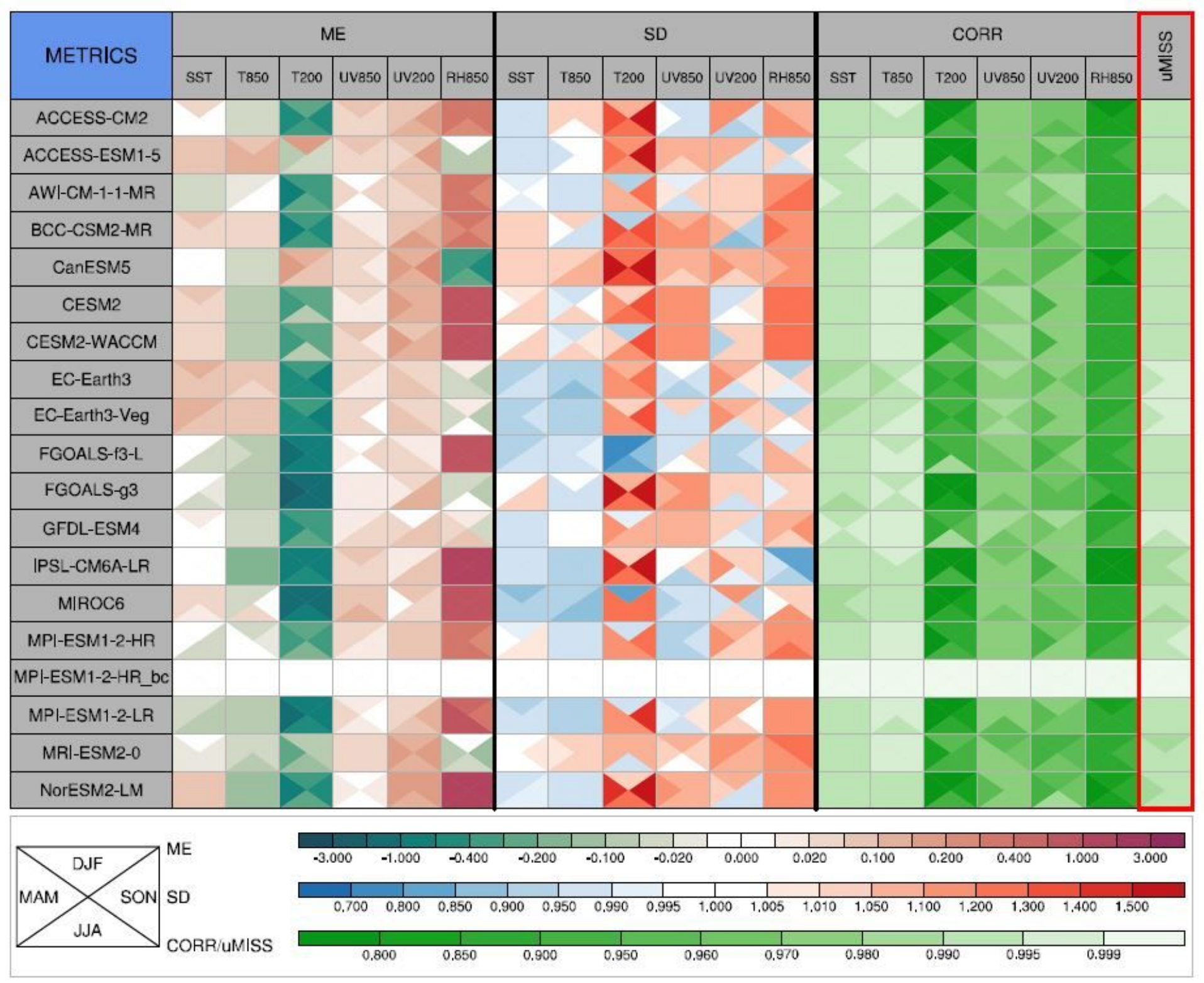

\section{Figure 3}

Statistical metrics that measure the performance of CMIP6 models in simulating climatological mean (1979 - 2014) of multiple variables. SST: sea surface temperature, T850: 850-hPa air temperature, UV850: 850-hPa vector wind, RH850: 850-hPa relative humidity, T200: 200-hPa air temperature, UV200: 200-hPa vector wind in the global. ME, SD, and CORR are the mean error, spatial standard deviation, and correlation coefficient of the climatological mean field, respectively. uMISS is the uncentered multivariable integrated skill score that summarizes the overall performance of a model in simulating multiple variables. All statistics are normalized by dividing the observed standard deviation of the corresponding variable. All models are evaluated against ERA5. Lighter color represents better model performance. MPI-ESM1-2-HR_bc is the bias-corrected GCM data. 
(a) SST ERA5

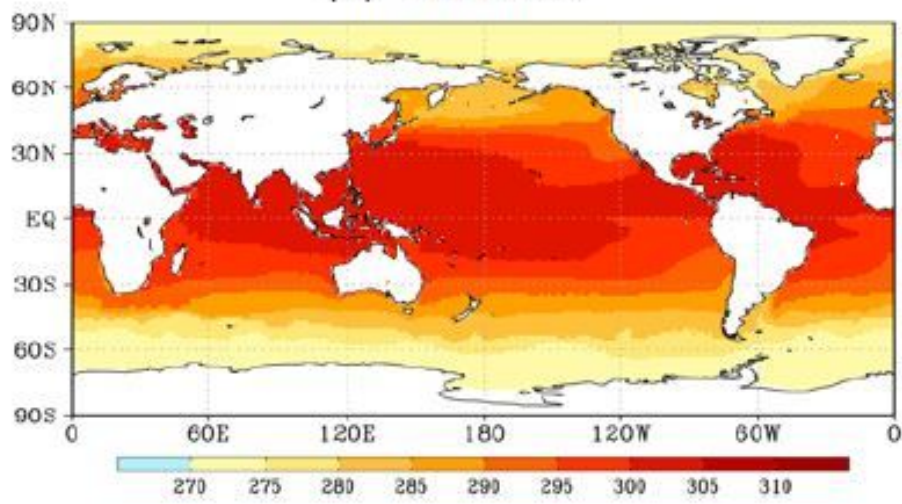

(c) SST GCM-ERA5

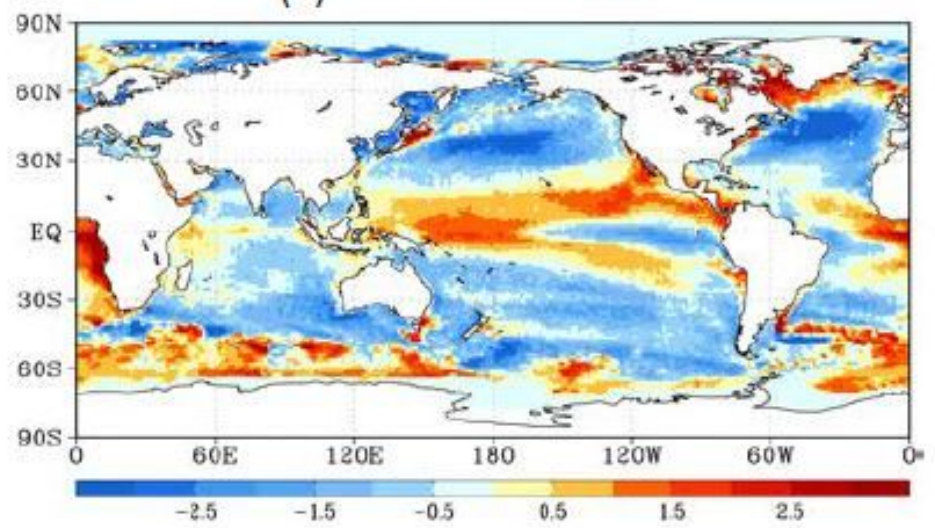

(e) SST GCMbc-ERA5

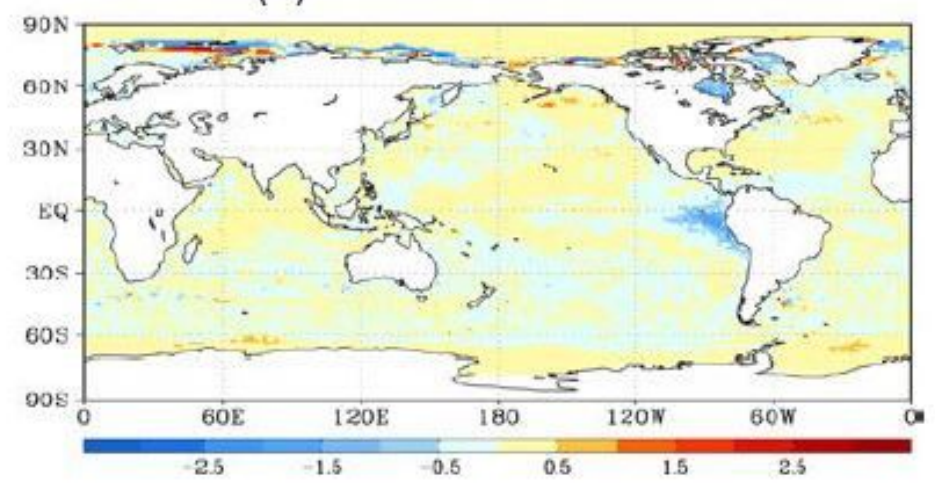

(b) Wind speed ERA5

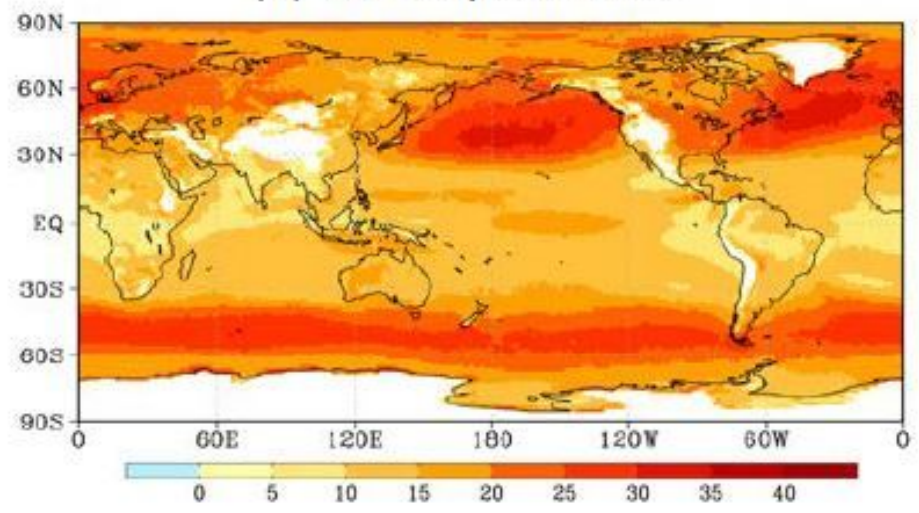

(d) Wind speed GCM-ERA5

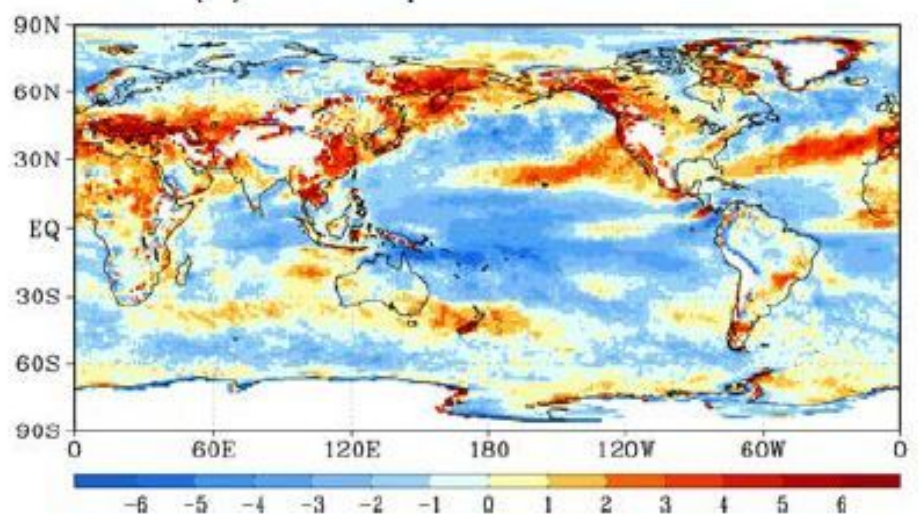

(f) Wind speed GCMbc-ERA5

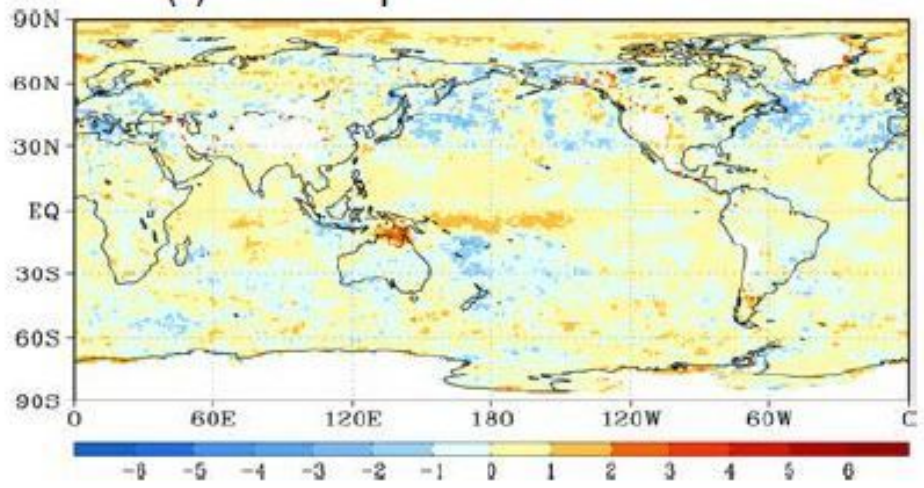

\section{Figure 4}

Comparison of the 95th percentile of daily SST $\left({ }^{\circ} \mathrm{C}\right)$ and 850-hPa wind speed wind (m s- 1$)$ during July of 1979-2014 against ERA5. (a, b) ERA5, (c-f) difference between GCM (GCMbc) and ERA5. Note: The designations employed and the presentation of the material on this map do not imply the expression of any opinion whatsoever on the part of Research Square concerning the legal status of any country, territory, city or area or of its authorities, or concerning the delimitation of its frontiers or boundaries. This map has been provided by the authors. 
(a) Nonlinear trends of 850 -hPa air temperature

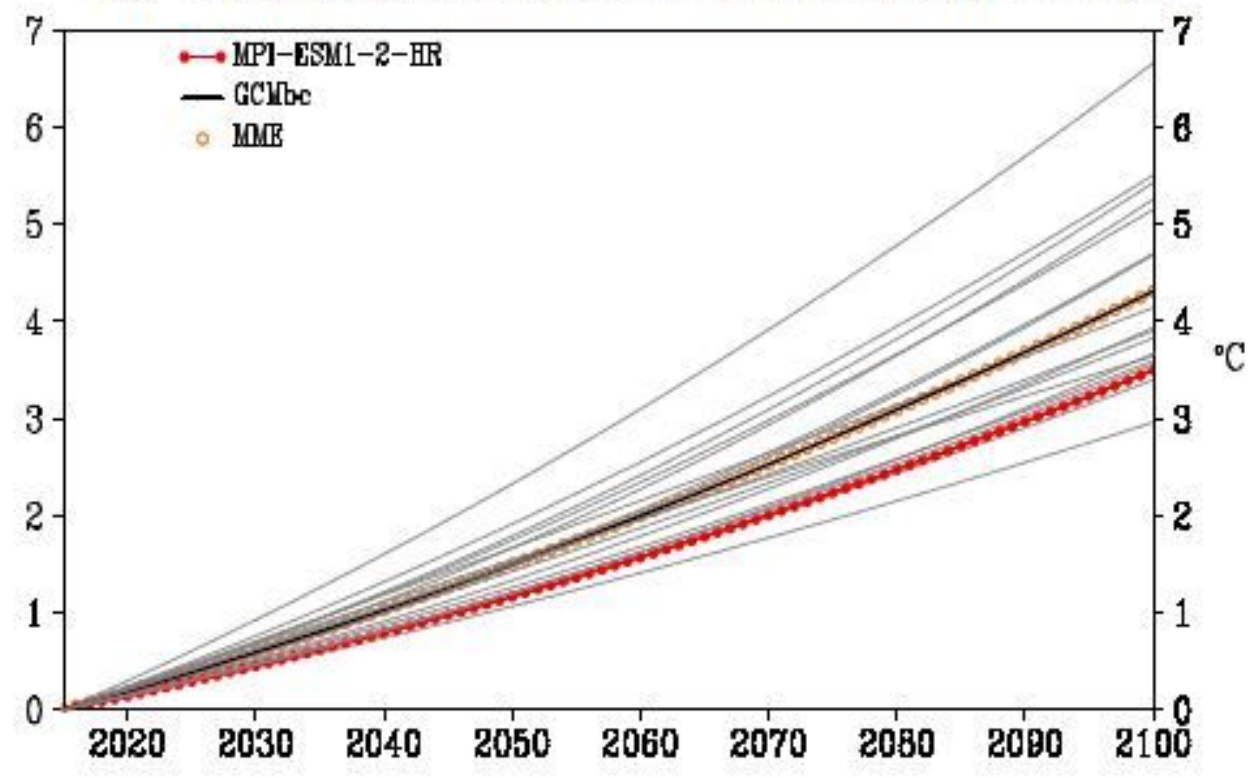

(b)RMSDs of nonlinear trend
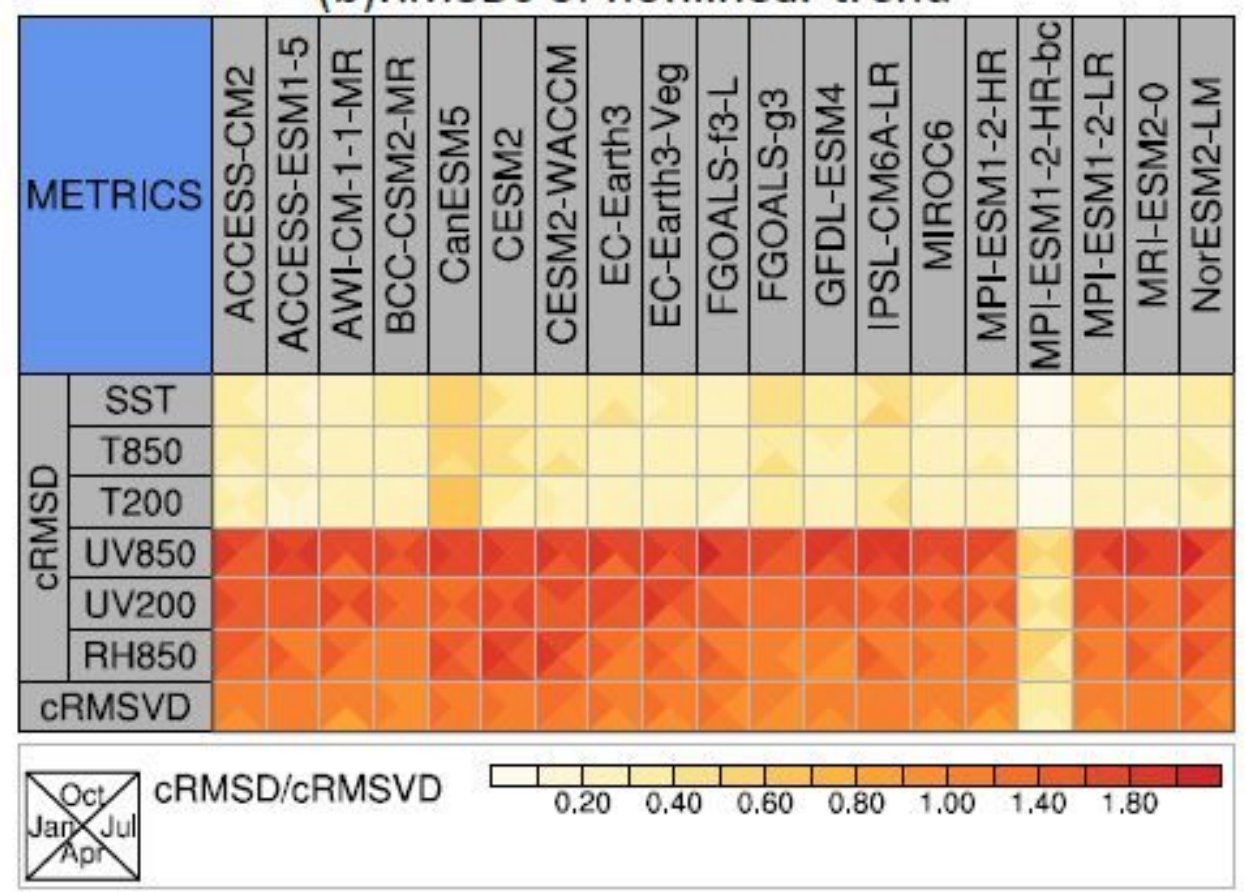

\section{Figure 5}

Comparison of Nonlinear trend of various CMIP6 data against multi-model ensemble mean (MME) in July from 2015 to 2100 under SSP585 scenario. (a) Global 850-hPa air temperature. The orange open circle, red solid circles, and the thick black line represent the MME, MPI-ESM1-2-HR model the biascorrected MPI-ESM1-2-HR model, respectively. The grey line indicates the other 17 CMIP6 models. The value of the non-linear trend in the year 2015 was subtracted from the original non-linear trend. (b) rootmean-square differences of the non-linear trends between the individual CMIP6 model and the MME. As 
in Fig. 3 the cRMSDs are also normalized by dividing the observed standard deviation of the corresponding variable. The cRMSVD represents the overall RMSD of all variables. The triangles in each grid cell represent the statistic in January, April, July, and October, respectively.

(a) global

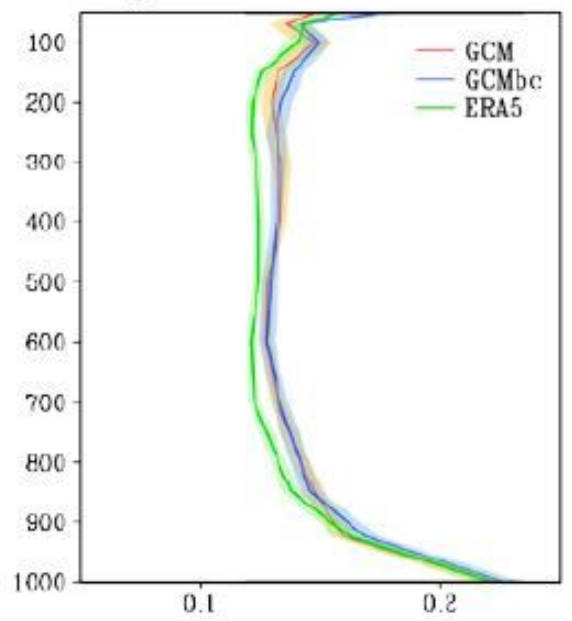

(d) High latitude NH

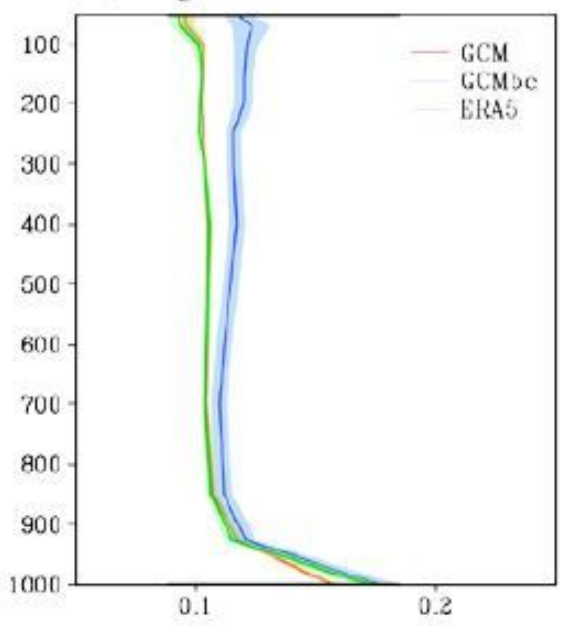

(b) Low latitude NH

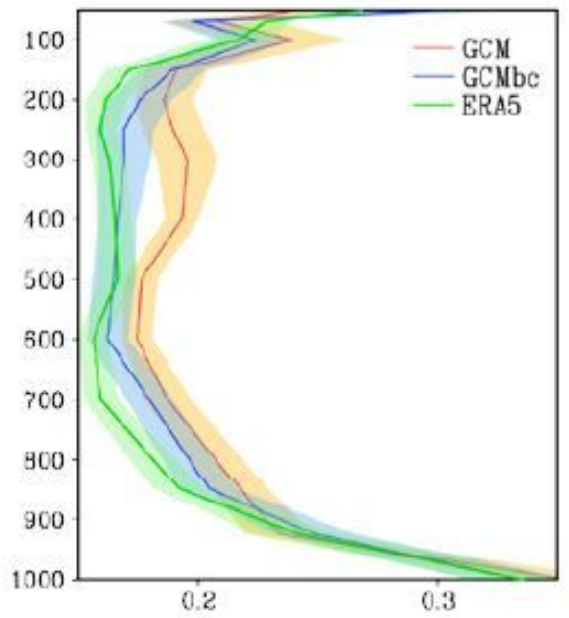

(e) East Asia

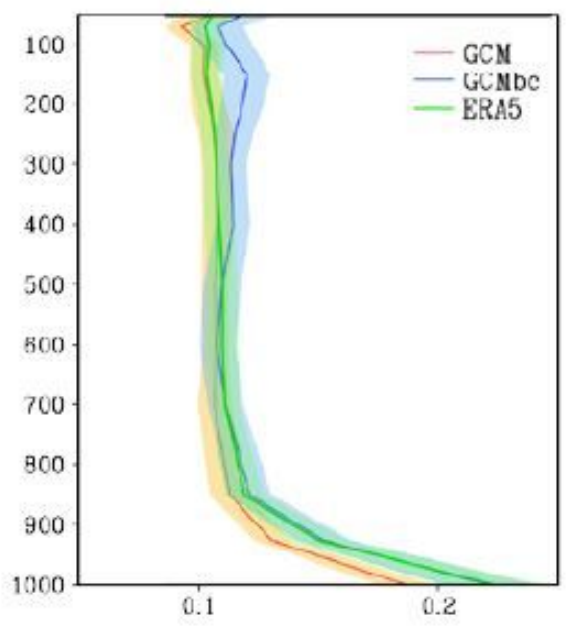

(c) Mid latitude $\mathrm{NH}$

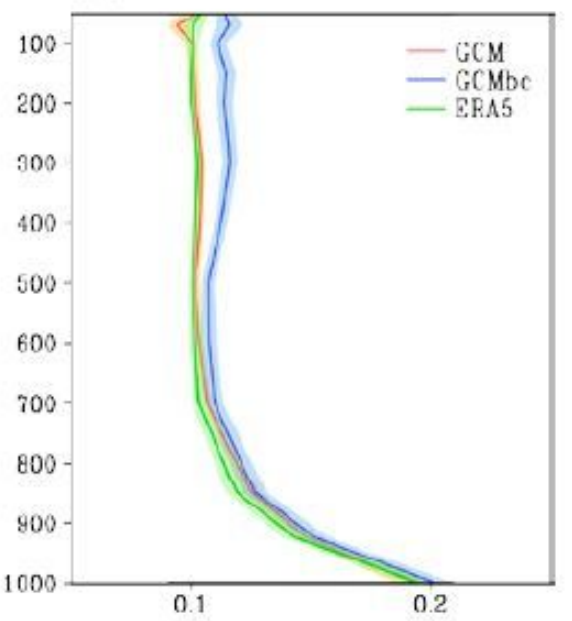

(f) Northwest Pacific

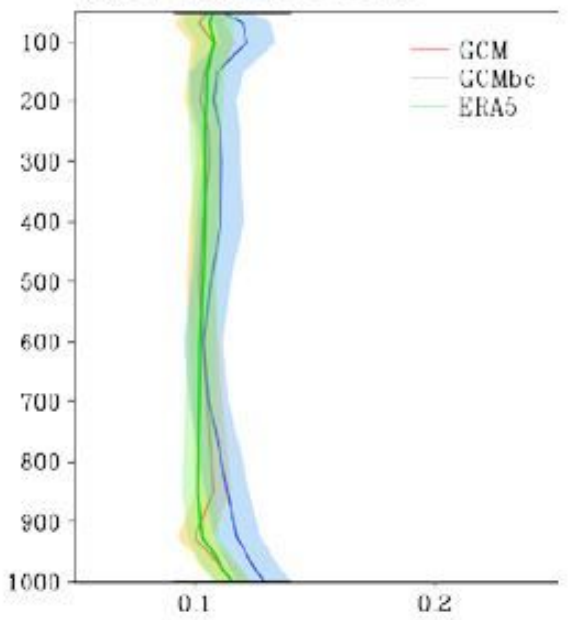

\section{Figure 6}

The ratio $(R)$ of ageostrophic wind speed to the real wind speed averaged over various regions in July 2014. The shading shows the one standard deviation. The ageostrophic wind and real wind are calculated using 6-hourly data in July 2014 . The area-mean $\mathrm{R}$ is computed in mid $\left(20^{\circ}-50^{\circ} \mathrm{N}, 0-\right.$ $\left.358.75^{\circ} \mathrm{E}\right)$ and high latitudes $\left(50-90^{\circ} \mathrm{N}, 0-358.75^{\circ} \mathrm{E}\right)$ of Northern Hemisphere, East Asia $\left(10^{\circ}-55^{\circ} \mathrm{N}\right.$, $\left.105^{\circ}-140^{\circ} \mathrm{E}\right)$, and Northwest Pacific $\left(10^{\circ}-40^{\circ} \mathrm{N}, 135^{\circ} \mathrm{E}-180^{\circ}\right)$. The grid cells with wind speed less than 2 $\mathrm{m} \mathrm{s}-1$ were excluded from the statistics. 